\title{
Orman Yangın Yönetiminde Etkili Bir Karar Destek Sisteminin Kavramsal Çerçevesi
}

\author{
Kadir Alperen Coşkuner ${ }^{1, *}$, Ertuğrul Bilgili ${ }^{1}$ \\ ${ }^{1}$ Karadeniz Teknik Üniversitesi, Orman Fakültesi, Orman Mühendisliği Bölümü, 61080, Trabzon.

\section{Özet}

Orman yangın organizasyonları, yangınlarla mücadelede başarılı olabilmek için doğru, güncel ve kolaylıkla elde edilebilir bilgilere ihtiyaç duyar. Bu bilgilerin temini, yangın risk ve tehlike potansiyeli ile yangın davranışı hakkında doğru ve hızlı bilgi verebilen kapsaml bir sistemin varlığl ile mümkün olabilir. Bu çalışmada, Türkiye orman yangın organizasyonu ve yangın yönetim planlamalarında kullanılabilecek bir Karar Destek Sisteminin (KDS) kavramsal çerçevesi, yapıst ve hiyerarşisi belirlenmiştir. KDS tasarımında, bir bütün halinde veya ayrı ayrı çalışabilecek dört alt sistem öngörülmüşürr. Bunlar; i) Yangın Bilgi Sistemi; orman yangınları ile ilgili mekânsal, zamansal ve tanımlayıcı bilgilerin depolandiğl ve veriler üzerinden akıllı sorgulamaların yapılabildiği alt sistem, ii) Yangın Çıkma İhtimalini Tahmin Sistemi; sabit ve değişken çevre faktörlerini dikkate alan ve belirli bir alan için yangin risk ve tehlike potansiyelini derecelendiren alt sistem, iii) Meteorolojik Yangın İndeksi Sistemi; yanıcı madde nemine bağlı olarak yanıcı maddelerin tutuşabilirliğini belirleyen ve yangının başlaması durumunda potansiyel yangın yayılma oranı ve yangın şiddeti hakkında bilgi veren alt sistem ve iv) Yangın Davranışı Tahmin Sistemi; yangın davranışını farklı hava halleri, topoğrafya ve yanıcı madde özelliklerine bağll olarak tahmin etmeye çalışan alt sistemidir. Geliştirilen sistem tasarımı uygulamada kullanılabilecek şekilde hazır hale geldiğinde, orman yangınları ile mücadelede yangın yöneticilerine yangın öncesi, yangınla mücadele ve yangin sonrası planlamalarda önemli katkllar sunacak potansiyeldedir.

\section{$\underline{\text { Anahtar Sözcükler }}$}

Karar Destek Sistemi, Orman Yangınları, Yangın Riski, Yangın Tehlikesi, Yangın Davranışı

\section{Conceptual Framework of an Effective Decision Support System in Forest Fire Management}

\begin{abstract}
Forest fire management organizations require accurate, timely and readily available information to be successful in forest fire suppression. A sound decision support system is necessary to acquire and make this information available to fire management organization. In this study, the framework, structure and hierarchy of a Decision Support System (DSS) was designed in forest fire management organization and planning in Turkey. DSS consists of four subsystems which can operate individually or collectively. These subsystems are; i) Fire Information System; a smart database for fire managers to input, store, update and manage data easily, ii) Fire Occurrence Prediction System; forest fire risk and danger determiner using constant environmental variables iii) Fire Weather Index System; fire weather index calculator for the ignition potential of fuels, potential rate of spread and fire intensity, iv) Fire Behavior Prediction System; fire propagation simulator for predicting fire behavior under varying weather, fuel and topographic conditions. When readily available for operational use, the DSS will have the potential to provide fire managers with tools and support necessary for successful fire prevention/presuppression, suppression and post fire management planning.
\end{abstract}

$\underline{\text { Keywords }}$

Decision Support System, Forest Fires, Fire Risk, Fire Danger, Fire Behavior

\section{Giriş}

Orman yangınları, yangına bağımlı ekosistemlerde ekolojik dengenin sağlanması ve birçok ekosistemin varlığını sürdürebilmesinde önemli bir faktördür (Bilgili vd. 2001; Moreira vd. 2011; San-Miguel-Ayanz vd. 2013). Ancak gerçekleşen yangınlar, her yıl dünya genelinde binlerce hektar orman alanının zarar görmesine ve ormana dayalı birçok ürün ve hizmetlerden yeterince yararlanılamamasına da sebep olmaktadır (Bilgili 1997; Küçük 2004; Sağlam 2002; Xanthopoulos 2007). Bu sebeple, yapılacak planlama ve düzenlemeler ile orman yangınlarının olumsuz etkilerinin azaltılması ve yangınların, yangına bağımlı ekosistemlerde bir yönetim aracı olarak kullanılabilmesi önem arz etmektedir (Martell vd. 1989). Orman yangın yönetim planlama ve uygulamaları, yangın organizasyonları tarafından gerçekleştirilmektedir (Taylor ve Alexander 2003). Orman yangınlarının yoğun olarak görüldüğü birçok ülke, orman yangın organizasyonlarını oluşturmuşlardır (Bilgili 1999). 
Bu organizasyonların görevi, yangın öncesi, yangınla mücadele ve yangın sonrası planlamalar yapmaktır (Burgan 1988; Deeming vd. 1978; Van Wagner 1987). Yangın yönetim planlamaları, genellikle yangın önleyici ve yangına hazırlıklı olmaya yönelik tedbirleri, çıkan yangınlarda uygulanacak ilk müdahale taktik ve stratejileri ile yangın sonrası faaliyetleri içeren geniş ölçekli planlamalardır (Martell 2001). Bu planlar, yangınların olası zararlarını en aza indirmek için yanıcı madde yönetim çalışmaları, yaban hayatı yönetimi ve diğer arazi yönetimi faaliyetlerinde kontrollü yakma çalışmalarının planlanmasını da içermektedir (Boer vd. 2009; Pyne 1984; Taylor ve Alexander 2003). Yangın yönetim planları oluşturulurken, birtakım yardımcı karar destek sistemlerden (KDS) de yararlanılmaktadır (Van Wilgen ve Burgan 1984).

Yangın yönetim planlarında sıklıkla kullanılan yardımcı KDS'ler genellikle “Orman Yangın Tehlike Oranları Sistemi (YTOS)" olarak anılmaktadır (Burgan 1988; Deeming vd. 1978; Stocks vd. 1989; Willis vd. 2001). Yangın riski; belirli bir alanda insan ya da doğal nedenlerin (yıldırım) varlığı ve etkisi ile belirlenen yangının başlama durumunun olasılığını ifade eder (Chuvieco vd. 2010; Çanakçığlu 1985; del Hoyo vd. 2011; Sağlam vd. 2008). Yangın tehlikesi ise genel olarak, yangın çıkabilecek alanlardaki topoğrafya gibi sabit, hava halleri ve yanıcı madde özellikleri gibi değişken çevre faktörlerinin durumları ile açıklanır (Merrill ve Alexander 1987; Wybo vd. 1995). Yangın tehlikesini etkileyen faktörlere bağlı olarak, mevcut şartlar altında oluşabilecek muhtemel bir yangının potansiyelinin belirlenmesi "Yangın Tehlike Oranı" olarak tanımlanır (Countryman 1966). Sabit ve değişken çevre faktörlerinden biri veya duruma göre birçoğu yangın tehlikesi üzerinde etkili olurlar (Merrill ve Alexander 1987). Yangın tehlikesi üzerinde etkisi olan bu faktörler, oluşturulan karar destek sistemlerinde sayısal olarak yangın tehlike indeksleri olarak belirtilerek, yangın yönetim planlamalarında rehber olarak kullanılır (Bilgili 1999; Küçük vd. 2007).

Orman Yangın Tehlike Oranları Sistemleri, model yapıları ve hiyerarşilerinde birtakım farklılıklar olmasına rağmen, genellikle üç ana bölümden oluşmaktadır (Sağlam 2002). Bu bölümler; orman yangını çıkmasına sebep olan faktörleri kullanarak yangın risk ve tehlike potansiyelini tahmin etmeye çalışan Yangın Çıkma İhtimali Tahmin Sistemi, meteorolojik faktörlere bağlı olarak yangın risk ve tehlike potansiyelini derecelendiren Meteorolojik Yangın İndeksi Sistemi ve hava halleri, topoğrafya ve yanıcı madde özelliklerine bağlı olarak yangın davranışını tahmin etmeye çalışan Yangın Davranışı Tahmin Sistemi’dir. Söz konusu sistemler, orman yangınlarının önemli bir problem oluşturduğu ülkelerde uzun yıllardır kullanılmaktadır (Bilgili vd. 2001; Küçük vd. 2007). Bu konuda öncülüğü, Amerika (Deeming vd. 1978; Deeming vd. 1972; Rothermel 1972), Kanada (Hirsch 1996; Lawson vd. 1985; Tymstra 2010; Van Wagner 1974) ve Avustralya (McArthur 1958, 1960) yapmış olup, birçok ülkede de bu konuda yoğun çalışmalar yürütülmektedir (de Groot, vd. 2006; Kalabokidis vd. 2016; Kalabokidis vd. 2012; Willis vd. 2001).

Dünya genelinde orman yangınlarının yönetiminde kullanılan karar destek sistemleri, bulundukları bölgenin iklim, topoğrafya ve yanıcı madde özellikleri ile yangın organizasyon yapısına bağlı olarak geliştirilmiş olup, sistem yapısı, kullanım kolaylığı ve farklı coğrafyalara uygulanabilirliği bakımından birbirlerine göre üstünlük ve eksiklikleri bulunmaktadır (Willis vd. 2001). Sistemlerin eksiklikleri genellikle, ölçülmesi veya elde edilmesi güç bazı girdilere ihtiyaç duyulması, sistem yapısının karmaşık yapıda olması ve sistem modellerinin ortaya çıkabilecek yeni durumlara uyarlanabilmesinin zorluğu ile ilgilidir (Taylor ve Alexander 2003). Ayrıca, kullanılan sistemlerin birçoğunun, gelişen teknolojilere bağlı olarak güncellenmesi gerekmektedir. $\mathrm{Bu}$ sebeple, sistemlerin yeniden tasarlanmasına yönelik çalışmalar yapılmaktadır (Fox-Hughes vd. 2018; Matthews vd. 2018; URL-1 2016).

Türkiye'de özellikle Batı Karadeniz sahil şeridinden başlayıp sırasıyla Marmara, Ege ve Akdeniz Bölgesinden Hatay'a kadar uzanan ve toplam orman alanının yaklaşık \%60'ını oluşturan 12 milyon hektarlık orman alanı, orman yangınlarına hassas bir yapıdadır. Bu alanlar için özellikle yaz aylarında meydana gelen orman yangınları, önemli bir orman koruma problemi oluşturmaktadır (OGM 2017). Ülkemizde orman yangınları ile mücadele, devlet eliyle Orman Genel Müdürlüğü (OGM) tarafından gerçekleştirilmektedir. Türkiye'de orman yangınlarına ilk müdahale ve söndürme çalışmalarında, diğer Avrupa ülkeleri ile kıyaslandığında (OGM 2016) ve yangın başına düşen yanan alan miktarı temel alındığında başarılı kabul edilebilir. Ancak, her yıl ortalama 20 bin hektarlık alanda etkili olan yangınların (OGM 2017) orman ekosistemi üzerindeki ekolojik etkilerinin yanında, mücadele masrafları ile birlikte sosyal ve ekonomik anlamda da birtakım kayıplar meydana getirdiği bilinmektedir (Bilgili 1997; Bilgili vd. 2001). Bu durum değerlendirildiğinde, orman yangınlarının hem ekolojik hem ekonomik hem de sosyal etkilerinin analiz edilmesine katkı sağlayabilecek karar destek sistemlerine ihtiyaç olduğu açıktır (Bilgili 1999). Ancak, karar destek sistemlerinin ülkemizde kullanılmasının önemi ve gerekliliği vurgulanmasına rağmen; dünya genelinde orman yangınları ile mücadelede kullanılan yangın tehlike oranları sistemleri gibi yardımcı karar destek sistemleri ülkemizde tam anlamıyla kullanılmamaktadır (Baş 1965; Bilgili ve Coskuner 2015; Çanakçıŏlu 1985, 1988; Mol 1988; Öymen 1989).

Yangın yönetim planlama ve mücadele çalışmalarında bir karar destek sisteminin oluşturulması için ülkemizde birtakım çalışmalar gerçekleştirilmiştir (Bilgili ve Sağlam 2003; Küçük 2000, 2004; Küçük vd. 2007; Sağlam 2002; TOGTAG 2008; TOVAG 2007, 2011, 2015). Yapılan çalışmalar kendi içinde bir önem ve bütünlük arz etmesine rağmen, geliştirilen sistemler bir karar destek sistemi halinde çalışabilecek yapıda değildir (Bilgili ve Coskuner 2015). Dolayısıyla, karar vericilere orman yangınları gibi sağlıklı karar vermenin son derece zor ve riskli olduğu durumlarda yardımcı olabilecek bir karar destek sisteminin Türkiye'de de hayata geçirilmesi önem arz etmektedir. Zira yangın risk ve tehlike potansiyelinin, yanıcı madde, hava halleri, topoğrafik özellikler, arazi kullanımı özellikleri ve geçmişe dönük yangın verileri ile önceden tahmin edilebilmesi, yangınlarda mücadele organizasyonun yapılmasında ve yangınların büyümeden söndürülmesi açısından önemlidir (Bilgili vd. 2001). 
Büyüme potansiyeli olan yangınların meteorolojik, topoğrafik ve meşcere özellikleri 1şı̆̆ında nasıl bir gelişim göstereceğinin önceden tahmin edilebilmesi ve yangın davranışının belirlenebilmesi, yangınla mücadele stratejilerinin belirlenmesinde son derece önemlidir. Ayrıca, bu bilgilerin yangın yöneticilerine sunulması ile yangınların bir yanıcı madde yönetimi aracı olarak kullanılabilmesi ve yangın yönetim planlarının kolaylıkla yapılabilmesi sağlanabilir (Bilgili 1999).

$\mathrm{Bu}$ çalışmasının temel amacı, Türkiye şartlarında kolaylıkla kullanılabilecek, güncel ve etkili bir orman yangın tehlike oranları karar destek sisteminin kavramsal çerçevesi, yapısı ve hiyerarşisinin oluşturulmasıdır.

\section{Materyal ve Yöntem}

Bu çalışmada, orman yangınlarının önemli bir orman koruma problemi oluşturduğu ülkelerin kullandığı Karar Destek Sistemlerinin (KDS) yapısı ve işleyişleri, kullanım kolaylıkları ve ihtiyaç duydukları veriler incelenmiştir. Yapılan inceleme ve değerlendirmeler neticesinde, Türkiye'nin yanıcı madde, hava halleri, topoğrafya ve demografik özellikleri değerlendirilerek, yangın organizasyonu ve yangın yönetim planlamalarında kullanılabilecek bir KDS'nin kavramsal çerçevesi, yapısı ve hiyerarşisi oluşturulmuştur.

\section{Bulgular ve Tartışma}

\subsection{Dünya Genelinde Orman Yangınları ile Mücadelede Kullanılan Karar Destek Sistemleri}

Karar destek sistemleri, bir karar aşamasında toplanmış bilgilerden faydalanarak karar vermeyi kolaylaştıran bilgisayar tabanlı sistemlerdir (Shim vd. 2002). Dünya genelinde orman yangınları ile mücadelede küresel, bölgesel ve ulusal ölçekte kullanılan karar destek sistemleri bulunmaktadır (Tablo 1). Bu sistemlerin büyük bir kısmı erken uyarı sistemleri olarak tasarlanmış ve kullanılmaktadır. Sistemlerin küçük bir kısmı ise orman yangınları ile mücadelede kullanılabilecek komple bir sistem olarak tasarlanmıştır.

Dünya genelinde kullanılan mevcut sistemler, arazi veya laboratuvar çalışmaları sonucunda belirli yanıcı maddeler için geliştirilmiş fiziksel veya deneysel (ampirik) modellerin ülke ihtiyaçlarına göre güncellenmesi ile oluşturulmuştur. Sistemlerin büyük bir bölümü orman yangınları ile mücadelede erken uyarı sistemi mahiyetinde olduğu için kullanılan modeller girdi olarak genellikle meteorolojik verileri kullanır. Meteorolojik verilerin modellerle yorumlanmas1 sonucunda elde edilen değerler ile yangın risk ve tehlike potansiyeli, bölgenin yangın istatistikleri, topoğrafya ve yanıcı madde özellikleri dikkate alınarak belirlenen ölçekler yardımıyla derecelendirilir (Chandler vd. 1983).

Tablo 1'de belirtilen karar destek sistemlerinden, Kanada Orman Yangın Tehlike Oranları Sistemi, ABD Ulusal Yangın Tehlike Oranları Sistemi ve McArthur Orman Yangın Tehlike İndeksi ayrıntılı olarak incelenmiştir. Zira orman yangınları ile mücadelede dünya genelinde kullanılan diğer Orman Yangın Tehlike Oranları Sistemlerinin model yapıları, bu sistemlere ilişkin modellerinin doğrudan kullanılması veya ülke yanıcı madde özelliklerine göre uyarlanarak kullanılması ile oluşturulmuştur.

\subsubsection{Kanada Orman Yangın Tehlike Oranları Sistemi}

Kanada Orman Yangın Tehlike Oranları Sistemi, Kanada Ormancılık Servisi tarafından ulusal yangın tehlike oranları sistemi olarak 1920'li yılların ortalarında yapılan çalışmalar ile geliştirilmeye başlanmıştır (Alexander vd. 1996; Stocks vd. 1989; Van Nest ve Alexander 1999). Sistem tasarımı 4 alt bileşenden oluşmaktadır (Şekil 1).

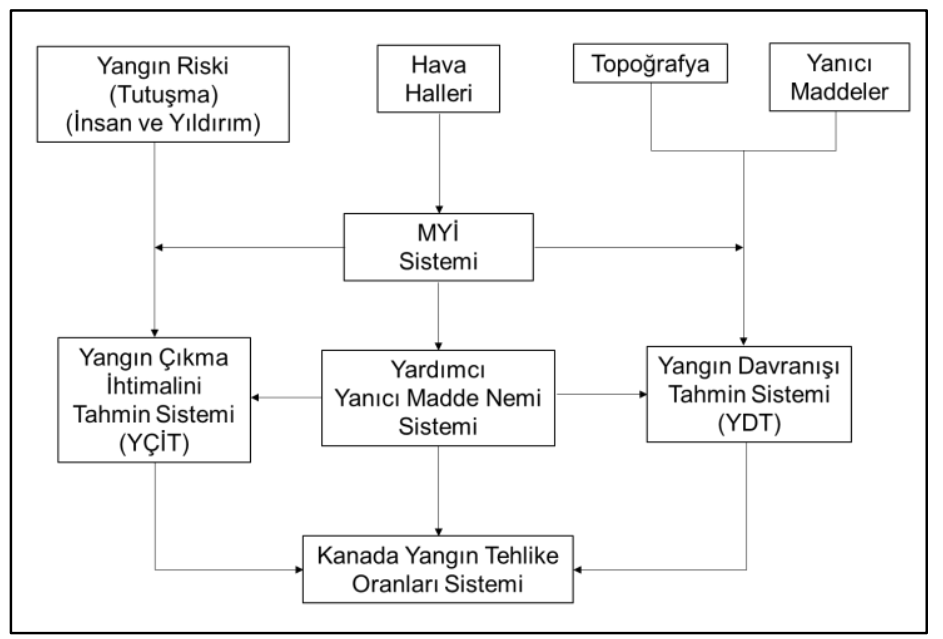

Şekil 1: Kanada orman yangın tehlike oranları sisteminin yapısı ve bileşenleri 
Tablo 1: Dünya'da orman yangınları ile mücadelede kullanılan karar destek sistemleri

\begin{tabular}{|c|c|}
\hline \multirow{4}{*}{ Küresel Ölçekli } & Küresel Orman Yangın Bilgi Sistemi (GWIS) \\
\hline & Yangın Riski ve Vejetasyon Koruma Sistemi (NOAA/NESDIS) \\
\hline & El Niño / Güney Asya Yangın Tahmin Sistemi (ENSO) \\
\hline & Küresel Toprak Nem İndeksi \\
\hline \multirow{8}{*}{ Bölgesel Ölçekli } & Güneydoğu Asya Bölgesel Yangın Tehlike Oranları Sistemi (SEA FDRS) \\
\hline & Yukarı Güneydoğu Asya (Tayland Hükümeti) Yangın Tehlike Oranları Sistemi \\
\hline & Kalimantan Yangın Tahmin ve Aktivite Bilgi Sistemi \\
\hline & Avrupa-Asya Meteorolojik Yangın Bilgi Sistemi \\
\hline & Avrupa Orman Yangın Bilgi Sistemi (EFFIS) \\
\hline & Alpine Orman Yangın Erken Uyarı Sistemi (ALPF FIRS) \\
\hline & Amazon Yangın Risk Sistemi (UCI-NASA) \\
\hline & Meksika ve Kita Amerika'sı Yangın Takip Sistemi \\
\hline \multicolumn{2}{|l|}{ Ulusal Ölçekli } \\
\hline Kanada & Kanada Yangın Tehlike Oranları Sistemi \\
\hline \multirow{3}{*}{ ABD } & Orman Yangınları Değerlendirme Sistemi (WFAS) \\
\hline & Ulusal Orman Yangın Tehlike Oranları Sistemi \\
\hline & Fırtına Tahmin Merkezi Meteorolojik Yangın Tahmin Sistemi (SPC) \\
\hline Avustralya & McArthur Orman Yangın Tehlike İndeksi \\
\hline Arjantin & Arjantin Yangın Tutuşma İndeksi \\
\hline Brezilya & Yangın Gözlem ve Tahmin Sistemi (NDVI) \\
\hline Finlandiya & Finlandiya Orman Yangın İndeksi Sistemi \\
\hline Almanya & Orman ve Çayır Yangın Tehlike İndeksi Sistemi \\
\hline Yunanistan & Yunanistan Yangın Tehlike İndeksi \\
\hline \multirow{3}{*}{ Endonezya } & Endonezya Yangın Tehlike Oranları Sistemi \\
\hline & Doğu Kalimantan Yangın Tehlike Oranları Sistemi \\
\hline & Sumatra Yangın Tehlike Oranları Sistemi \\
\hline \multirow{2}{*}{ İtalya } & Bölgesel Veneto Yangın Tehlike Oranları Sistemi \\
\hline & Sardunya Orman Yangın Erken Uyarı Sistemi \\
\hline Güney Kore & Güney Kore Orman Yangın Tehlike Oranları Sistemi \\
\hline Malezya & Malezya Yangın Tehlike Oranları Sistemi \\
\hline Meksika & Orman Yangın Bilgi Sistemi \\
\hline Hollanda & Hollanda Anlık Doğal Afet Risk Belirleme Sistemi \\
\hline Yeni Zelanda & Meteorolojik Yangın Tahmin Sistemi \\
\hline Polonya & Polonya Orman Yangın Tehlike İndeksi \\
\hline Portekiz & Orman Yangın Önleme Meteorolojik Destek Sistemi \\
\hline Rusya & Rusya Meteorolojik Yangın Risk Belirleme Sistemi \\
\hline \multirow{2}{*}{ Güney Afrika } & Net Tahmin Sistemi \\
\hline & Zululand Meteorolojik Yangın İndeksi \\
\hline İsveç & Orman ve Çayırlık Yangın İndeksi \\
\hline \multirow{2}{*}{ Tayland } & Tayland Yangın Tahmin Sistemi \\
\hline & Günlük Yangın Tehlike Oranları Haritalama Sistemi \\
\hline Ukrayna & Ulusal Yangın Tehlikesi Tahmin Sistemi \\
\hline Vietnam & Vietnam Orman Yangın Erken Uyarı Sistemi \\
\hline
\end{tabular}

Sistemin önemli iki bileşenini Meteorolojik Yangın İndeksi (MYİ) Sistemi (Van Wagner 1987, 1998) ve Yangın Davranışı Tahmin Sistemi (YDT) (CFDG 1992; Taylor ve Alexander 2003) oluşturur. Kanada YTO sistemi, uzun yıllar orman yangınları ile mücadelede sadece MYİ sistemi ve bileşenlerini temel alarak kullanılmıştır (Van Wagner 1974). Kanada MYİ sistemi, yanıcı maddelerin tutuşabilirliğini belirler ve yangının başlaması durumunda potansiyel yangın yayılma oranı ve yangın şiddeti hakkında bilgi verir (Van Wagner ve Pickett 1985) (Şekil 2). 


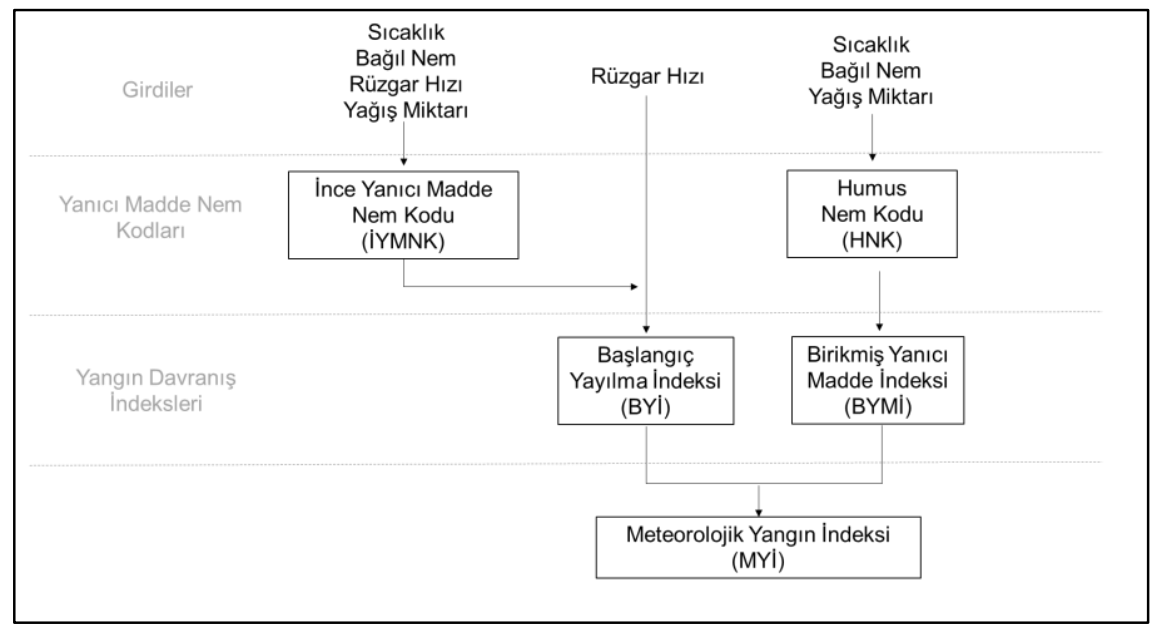

Şekil 2: Kanada YTO sisteminin ana bileşeni olan MYI sisteminin yapısı ve bileşenleri

Sistem, standart bir yanıcı madde tipinde yangın risk ve tehlike potansiyelini derecelendirmektedir. Bu sebeple MYİ sistem çalışmaları, ağırlıklı olarak Kanada orman ekosistemlerinde yaygın olarak bulunan Banks çamı (Pinus banksiana) ve Kontorta çamı (Pinus contorta) üzerine yoğunlaştırılmıştır. Yangınların büyük ve önemli bir kısmı bu iki türün saf veya karışımda bulunduğu meşcerelerde meydana gelmektedir (Rowe 1972). Kanada MYİ sistemi hesaplamasında, hava hallerinden sadece sıcaklık, bağıl nem, yağış miktarı ve rüzgâr hızı girdi olarak kullanılır. Bu verilerin rahatlıkla elde edilebilmesi ve belirli bir alan için yangın risk ve tehlike potansiyelinin kolaylıkla hesaplanması sistemin kullanışlılığını arttırmaktadır.

Sistemin diğer önemli bileşeni olan Yangın Davranışı Tahmin (YDT) sisteminin temelinde yer alan modeller, yoğun arazi çalışmaları ve doğal yangınlarda yangın davranışının gözlenmesi ile oluşturulmuştur (Alexander vd. 1996; Stocks vd. 1989). YDT sisteminde, Kanada ekosistemlerini temsil eden 16 farklı yanıcı madde tipi için yanıcı madde modelleri kullanılmaktadır. Mevcut durumda YDT sistemi, yangın yöneticilerinin kullanabileceği bir yangın davranışı benzetim yazılımı (Prometheus) olarak kullanılmaktadır (Tymstra 2010).

Kanada YTO sistemi tasarımında yapımı planlanan iki alt sistem daha bulunmaktadır. Bunlardan ilki, Kanada'nın faklı bölgelerinde yıldırım ve insan kaynaklı yangınları tahmin etmesi amaçlanan Yangın Çıkma İhtimali Tahmin Sistemi (YÇIT)'dir. YÇİT sistemine yönelik Kanada'nın belirli bölgelerinde ve özellikle yıldırım kaynaklı yangınların tahmin edilmesine yönelik çalışmalar bulunmaktadır (Kourtz ve Todd 1991; Martell vd. 1989). Ancak sistem henüz ülke genelinde kullanılabilecek bir yapıda değildir (Lee vd. 2002).

YTO sistemi içerisinde planlanan diğer alt sistem ise, diğer üç ana sisteme, yanıcı maddelerin durumu hakkında bilgi sağlaması amaçlanan Yardımcı Yanıcı Madde Nemi Sistemi'dir. Bu sistemin iki amacı bulunmaktadır; i) belirlenen standart yanıcı maddenin dışında, orman yangınları açısından önem arz eden kesim artıkları, otlar, liken vb. diğer yanıcı maddelerin nem durumu hakkında bilgi vermek, $i$ ) arazi yüzü şekli, enlem-boylam, mevsim (mevsime göre arazideki canlı yanıcı maddenin türü ve durumu vb.) gibi özellikler hakkında bilgi vermektir. Ancak bu sistem de tasarım aşamasında olup, henüz kullanılmamaktadır (Stocks vd. 1989).

Kanada YTO sisteminin en önemli bileşeni olan MYİ sistemine ek olarak, MYİ sisteminden almış olduğu yanıcı madde nem kodları ile yangın davranış indeksleri yardımıyla yanıcı madde özellikleri, topoğrafya ve hava hallerine bağlı olarak yangın davranışını tahmin eden YDT sisteminin oluşturulması, sistemin farklı bölge ve ülkelerde kolaylıkla kullanılmasını zorlaştırmışıı (Willis vd. 2001). Özellikle YDT sistemindeki yangın davranış modellerinin farklı yanıcı madde tiplerine göre tahmin gerçekleştirmesi ve mevcut modellerin diğer ülkelerdeki yanıcı madde tiplerine uyarlanmasının görece zorluğu bu durumun en önemli nedenidir. Ancak, Kanada MYİ sistemi hala farklı bölge ve ülkelerde yaygın olarak kullanılmaktadır.

Kanada YTO sistemi, Yeni Zelanda, Fiji, Alaska, Venezüella, Meksika, Şili, Arjantin, Endonezya, Malezya ve Avrupa'daki birçok ülkede test edilmiş ve ülke yanıcı madde özelliklerine göre uyarlanarak kullanılmaktadır (Dimitrakopoulos vd. 2011; GOFC-GOLD 2003; Viegas vd. 1999). Sistem, söz konusu ülkelerin yangınlarla mücadele birimlerinde, orman yangınlarına yönelik yangın önleme ve yangın yönetim planlarına katkı sağlamaktadır (de Groot vd. 2006). Bu durum, sistem yapısının dünya geneline uyarlanabileceği konusunda bir öngörü oluşturmaktadır (Fogarty vd. 1998).

Güney Akdeniz'deki bazı Avrupa ülkeleri, Kanada YTO sisteminin alt sistemi olan MYİ sisteminin, Avrupa genelinde kurulacak ve 3 günlük yangın risk ve tehlike potansiyelini belirtecek olan Avrupa Orman Yangın Bilgi Sistemin (EFFIS) resmi altlığı olmasını talep etmişlerdir (Lopez vd. 2002). Günümüzde, Avrupa genelinde yangın risk ve tehlike potansiyeli tahmini yapan EFFIS (URL-2 2018) sistemi, Kanada MYİ sistemine küçük uyarlamalar yapılarak oluşturulmuş bir sistemdir. 
EFFIS sistemin geliştirilerek dünya genelinde kuraklık ve yangın tehlike potansiyeli tahmini yapmasına yönelik çalışmalar yapılmıştır (Pettinari 2015). Bu çalışmaların sonucunda, Avrupa komisyonunun Kopernikus Programı Acil Durum Yönetimi Birimi bünyesinde bulunan Küresel Orman Yangınları Bilgi Sistemi (GWIS) oluşturulmuştur. Oluşturulan GWIS sistemi mevcut EFFIS sistemi, Küresel Karasal Gözlem Sistemi (GTOS), Orman Örtüsünün Küresel Gözlenmesi - Karasal Dinamikleri Küresel Gözlemlenmesi (GOFC-GOLD), Orman Yangını Yürütme Ekibi (GOFC Fire IT) ve bölge ülkelerinin desteği ile oluşturulmuştur. Ayrıca GWIS sistemi, Amerikan Ulusal Havacılık ve Uzay (NASA) Dairesi’nin Dünya Gözlemleri Çalışma Grubu Programı tarafından da desteklenmektedir. Sistem bünyesinde kullanılmak üzere uydu görüntüleri yardımıyla dünya geneli Küresel Yanıcı Madde Sınıflandırma Sistemi (FCCS) oluşturulmuştur. Toplamda oluşturulan 274 farklı yanıcı madde tipinin, GWIS sisteminin yangın davranışı, yanıcı madde tüketimi, karbon salınımının değerlendirilmesi gibi çalışmalarda kullanılması planlanmaktadır. GWIS sistemine çevrimiçi ulaşılabilmektedir (URL-3 2018).

Yeni Zelanda, Kanada MYİ sistemini ülkedeki egzotik çam plantasyonu sahalarında kullanılmak üzere 1978 yılında adapte etmiştir (Pearce ve Alexander 1994). Sistemin ilk yıllarında çam plantasyonları için oldukça başarılı sonuçlar elde edilmiş ve daha sonra mevcut sistemin makilik alanlar dâhil, ülke genelindeki tüm yanıcı madde tiplerinde kullanılmasına karar verilmiştir. Ancak yeterince başarılı sonuçlar alınamamıştır. Daha sonra ülkeye özgü yanıcı madde tipleri için MYİ sisteminde kullanılacak yanıcı madde modelleri geliştirmek için 1992 yılında bir araştırma programı başlatılmıştır (Fogarty vd. 1998).

Kanada/Ontario Doğal Kaynaklar Bakanlığı, 1981 ve 1991 yılları arasında Çin’in kuzeydoğusunda kullanılmak üzere model bir YTO sistemi için araştırma programı gerçekleştirmiştir (White ve Rush 1990). Ancak Çin'in farklı kültürel ve yönetimsel yapısı nedeniyle, Kanadalı uzmanlar birçok problem ile karşılaşmışlardır. Yangınlarla mücadeleye yönelik alınan kararların sadece üst düzey yöneticiler tarafından verilmesi ve yangınlara müdahale konusunda topyekûn müdahale seçeneğinin benimsenmesi, sistemin ülkede kurulmasını engellemiştir. Ayrıca, Kanada yapımı elektronik sistemler ve otomatik meteoroloji istasyonlarının, Çin'de bakım ve onarım problemleri ortaya çıkmıştır (Dimitrakopoulos vd. 2011).

Kanada sistemi kullanım kolaylığı ve yangınlarla mücadelede sunmuş olduğu farklı çıktılar sebebi ile Meksika, Güneydoğu Asya ve ABD - Florida'da da yaygın bir şekilde kullanılmaktadır (Lee vd. 2002). Arjantin'de Ulusal Orman Yangın Yönetim Planlarının Kanada MYİ sistemi ile yapılmasına yönelik 2001 yılında proje gerçekleştirilmiş ve 3 pilot alanda planlamalar yapılmıştır (Taylor 2001).

Endonezya ve Malezya'da kullanılan YTO sistemi, Kanada YTO sistemin ülke yanıcı madde tipleri, iklim ve yangın rejimi şartlarını uyarlanmış halidir. Söz konusu ülkelerde gerçekleştirilmiş olan sistem, Kanada MYİ sisteminin yanında Kanada Yangın Davranışı Tahmin (YDT) sistemi de barındırmaktadır. Kurulan sistem ülke genelinde, orman yangınları ile mücadelede strateji geliştirmek, yangın önleme ve müdahale planların yapılmasında kullanılmaktadır (de Groot 2006).

Portekiz ve İspanya gibi birçok Avrupa ülkesi Kanada YTO sistemi bileşenlerinin, Akdeniz ekosistemlerine uyarlanmış halini kullanmaktadır. Yapılan çalışmalarda, Kanada MYİ sisteminin Güney Portekiz, İspanya, Fransa ve İtalya'da çıkan yangınlar için yüksek korelasyonlu sonuçlar verdiği belirlenmiştir (Viegas vd. 1999). Ancak özellikle Güney Avrupa'daki nispeten daha kurak Akdeniz coğrafyalarında, sistemin daha kapsamlı şekilde test edilmesi gerekliliği, yapılan çalışmalarla ortaya konulmuştur (Dimitrakopoulos ve Bemmerzouk 2003).

\subsubsection{ABD Ulusal Yangın Tehlike Oranları Sistemi}

ABD Ulusal Yangın Tehlike Oranları Sistemi'nin (NFDRS), temelini Rothermel'in 1972 yılında geliştirmiş olduğu yangın davranış modeli oluşturmaktadır (Rothermel 1972). ABD Ulusal YTO sistemi ülke genelinde ilk defa 1972 yılında kullanılmıştır (Deeming vd. 1972). Sistem, 1978 yılında büyük oranda güncellenmiş (Deeming vd. 1978) ve 1988 yılında ise yanıcı madde nem tahmini konusunda yine bir güncelleme yapılarak uzun süre kullanılmıştır (Burgan 1988). Sistemin ana yangın yayılma modeli Güney Afrika, Avrupa, Asya ve Avustralya kıtalarında test edilmiş ve başarılı sonuçlar elde edilmiştir (Willis vd. 2001).

ABD Yangın Tehlike Oranları Sistem modelleri, ülke genelinde farklı yanıcı madde tipleri ve hava halleri için uyarlanmış ve kullanılmaktadır. Sistem, temel olarak fiziksel yangın davranış modellerini esas almaktadır. Bu modellerin avantajı, temel yanma süreçlerini (enerji salınımı vb.) içermesidir. Modellerin dezavantajı ise son derece karmaşık bir yapıda olması ve ortaya çıkabilecek yeni durumlara karşı modellerin uyarlanabilmesin zor olmasıdır. Sistemin yapı ve işleyişi Şekil 3'te gösterilmiştir.

Amerikan Ulusal YTO Sisteminin bir diğer olumsuz yanı ise ölçülmesi ve elde edilmesi zor olan bulutluluk ve yağış süresi gibi verilere ihtiyaç duymasıdır. $\mathrm{Bu}$ durum sistemin basit bir şekilde farklı alanlarda kullanılmasını engellemektedir. Ancak, sistemdeki yanıcı madde modelleri birçok yanıcı madde tipini ve ayrıca canlı yanıcı madde nemini de kapsamaktadır. Bu durum özellikle tepe yanıcı madde miktarının fazla olduğu maki gibi yanıcı madde tiplerinde tepe yangınlarının tahmin edilmesine yardımcı olmaktadır. 


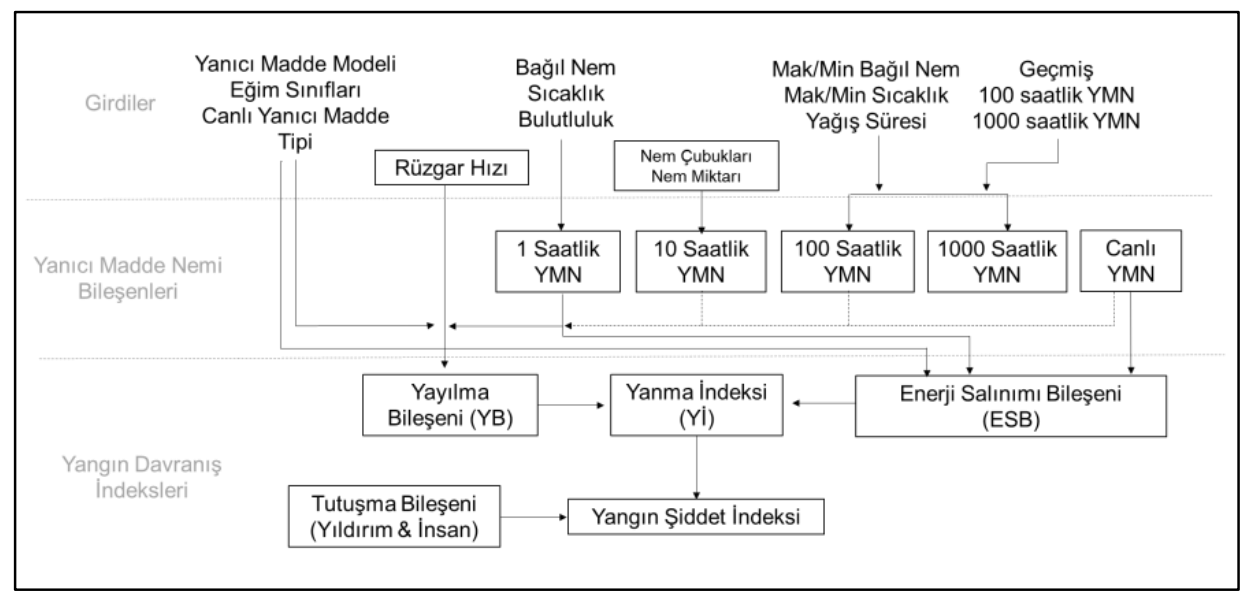

Şekil 3: ABD Ulusal YTO sisteminin yapısı ve bileşenleri (YMN: Yanıcı Madde Nemi)

Sistemin çıktıları, Yayılma Bileşeni (YB), Enerji Salınımı bileşeni (ESB) ve Yanma İndeksi (YI)'dir. Yapılan çalışmalar sonucunda, sisteme tutuşma bileşenleri de eklenmiştir (Burgan 1988). Böylece, yangının orman ekosistemine olan etkisinin bir göstergesi olan Yangın Şiddet İndeksi hesaplanabilmektedir. Sonuç olarak ABD YTO sistemi yayılma, enerji salınımı, yanma, insanın tutuşmaya etkisi, yıldıımların tutuşmaya etkisi ve yangın şiddeti olmak üzere 6 adet indeks çıktısı verebilmektedir.

ABD YTO Sisteminin, gelişen teknolojiler yardımıyla ve uzun yıllardır edinilen tecrübe ile önemli oranda güncellenmesi planlanmaktadır (URL-1 2016). Sistemin yapı ve işleyişinde önemli bir değişiklik yapılmamakla birlikte, kullanım zorluğu nedeniyle yanıcı madde model sayılarının 40'tan 4'e indirilmesi önerilmişstir. Ayrıca 1970'li yıllarda geliştirilen ve uzun süre kullanılan ölü örtü yanıcı madde nem tahmin modellerinin (Fosberg ve Micheal 1971; Fosberg vd. 1971), zamanın koşulları ve yapılan analizler (Carlson vd. 2007) sonucunda yeni yanıcı madde nem modelleri (Nelson 2000) ile güncellenmesine yönelik çalışmalar yapılmaktadır.

\subsubsection{McArthur Orman Yangın Tehlike Indeksi}

Avustralya'da yangın tehlike oranları ilk olarak 1936 yılında kullanılmıştır (McArthur 1958). Güneydoğu Avustralya'da 1939 yılında gerçekleşen büyük bir yangın sonrası, yangınlarla mücadeleye ve yangın araştırmalarına ağırlık verilmiş, bunun sonucunda 1958 yılında McArthur'un Orman Yangın Tehlike İndeksi (YTİ) ortaya çıkmıştır. Model geliştirmeleri günümüze kadar devam etmiş olup (McArthur 1958; 1960; 1962; 1966; 1967) günümüzde sistemin Mark IV sürümü Güneydoğu Avustralya'da kullanılmaktadır. Söz konusu indeks, yangınlara müdahalede zorluk derecelerini 6 sınıfa ayırmaktadır (Düşük, Orta, Yüksek, Çok Yüksek, Ekstrem ve Afet). McArthur Orman YTİ'nin yapısı ve işleyişi Şekil 4 'te gösterilmiştir.

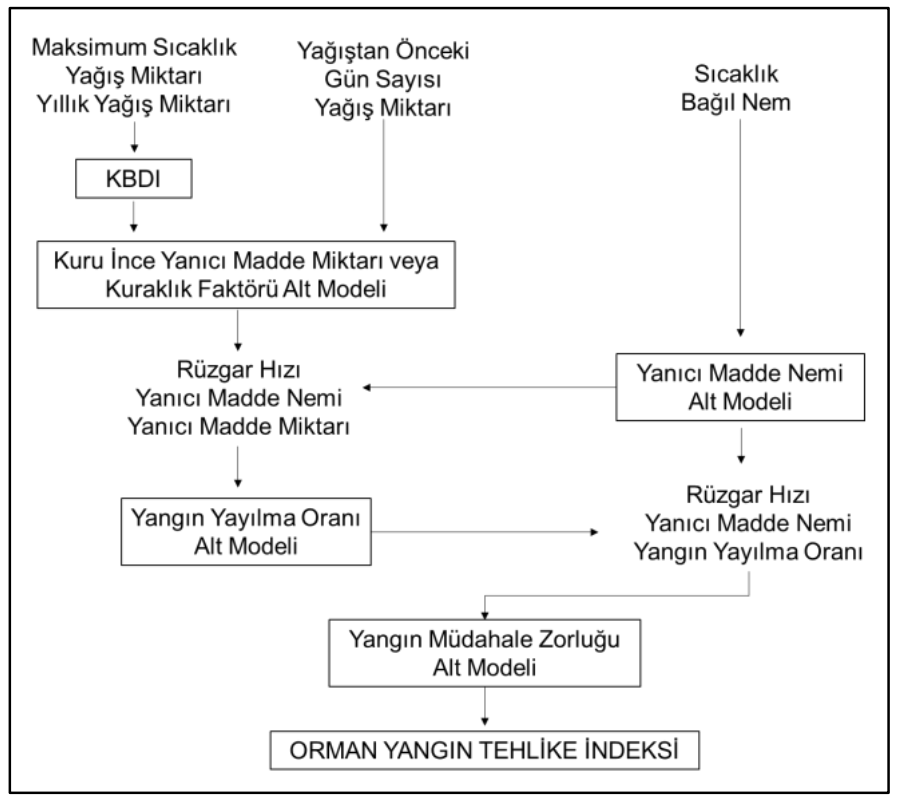

Şekil 4: McArthur Orman Yangın Tehlike Indeksinin yapısı ve girdileri (KBDI: Keetch-Byram Kuraklık Indeksi) 
Sistem, çalışabilmek için hava sıcaklığı, bağıl nem, rüzgâr hızı, yağış miktarı, yağıştan önceki gün sayısı ve KeetchByram (KBDI) (Keetch ve Byram 1968) kuraklık indeks değeri bilgilerine ihtiyaç duyar. KBDI ise, girdi olarak günlük maksimum sıcaklık, günlük yağış miktarı, bir önceki günün KBDI değeri ve ortalama yıllık yağış miktarını kullanır.

İndeks değeri, hektardaki yanıcı madde miktarı 12 ton olan, düz ve açık okaliptüs ormanında gerçekleşen yangının nispi yangın yayılma oranıdır. Diğer yanıcı madde tiplerinde ise, indeks değeri ile yangın yayılma oranı farkına bağlı olarak hesaplama yapılmaktadır (McArthur 1967). Sistemin sağlamış olduğu indeks değeri, yangınla mücadele zorluğuna göre düşükten (yangına müdahalenin kolay olduğu durum), ekstreme (yangına doğrudan müdahalenin, yangının yayılma oranının yüksek olması ve yangın hattının önünde meydana gelen yoğun yangın atmalarından dolayı mümkün olmadığı durum) doğru derecelendirir (McArthur 1962).

McArthur'un Yangın Tehlike İndeksinin temelinde, açık ormanlık alanlardaki yangın davranışını belirleyen ampirik model tipi bulunmaktadır. Ancak indeks, bütün ormanlık alanlar için uyarlanmış ve kullanılmaktadır. Yangın davranışı, farklı yanıcı madde tiplerinde farklılık gösterse de, genel olarak diğer alanlar için de yangın tehlikesi ortaktır. Farklı yanıcı madde tiplerinin açık ormanlık alanlara uyarlanması, yangın tehlike sınıf aralıklarının yanıcı madde tiplerine göre değiştirilmesi ile gerçekleştirilir. Ancak, Avustralya'da çayır ekosistemlerinin fazlalığı, bu alanlarda yangın tehlikesin yüksek olması ve ayrıca yangınların yerleşim alanlarını tehdit etmesi sebebi ile çayır yanıcı madde tipi için yeni bir yangın tehlike indeksi geliştirilmiştir.

McArthur'un Çayır YTİ'si, temelde Orman YTI'si ile aynıdır. Ancak bu indeks değeri için kuru yanıcı madde neminin hesaplatılmasında, Kuraklık İndeksi ve Kuraklık Faktörünün yerine, çayırın kuruma derecesi girdi olarak kullanılır (Griffiths 1999) (Şekil 5). Çayır kuruma derecesi, toplam kuru (ölü) çayır ağırlığının, yeşil (canlı) çayır ağırlığına oranı ile hesaplanmaktadır (McArthur 1960). Sistemin yapısı ve bileşenleri Şekil 5 'te gösterilmiştir.

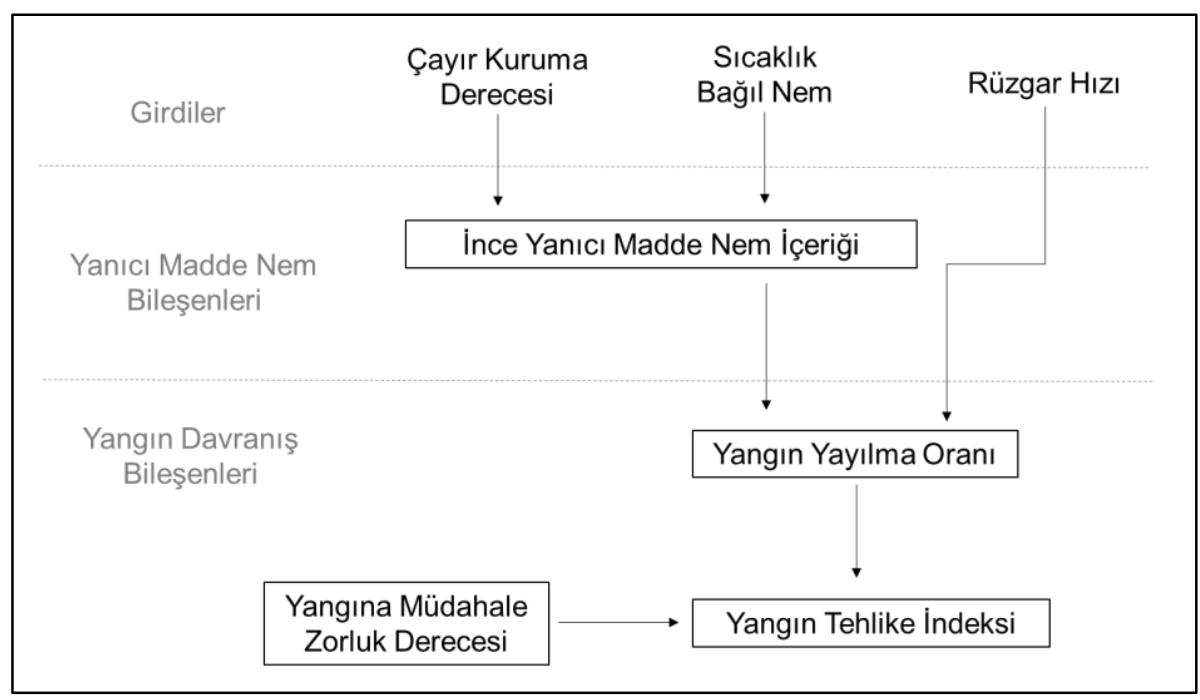

Şekil 4: McArthur çayır yangın tehlike indeksinin yapısı (Mark IV)

Sistemin Mark V sürümüne çayır yanıcı madde miktarı eklenmiştir. Ancak yapılan çalışmalar ile yeni sürümünün Mark IV sürümünden daha başarılı sonuçlar vermediği gözlenmiştir (Willis vd. 2001). Bu yüzden Avustralya'da genellikle Mark IV sürümü kullanılmaktadır.

Avustralya Ormancılık Birimi ve Üniversiteler tarafından 2014 yılında yapılan değerlendirmeler sonucunda, yeni bir yangın tehlike oranları sisteminin, zamanın koşulları ve gelişen teknolojiler neticesinde geliştirilmesi gerekliliği kararlaştırılmıştır (Matthews vd. 2018). 1960'lı yıllarda geliştirilen mevcut sistemin yerine, yeni bir yangın tehlike oranları sisteminin kurulmasına yönelik çalışmalar yapılmaktadır. Çalışmalar neticesinde geliştirilen model yangın tehlike oranları sistemi, henüz deneme aşamasındadır (Fox-Hughes vd. 2018).

\subsection{Dünya Genelinde Kullanılan Orman Yangın Tehlike Oranları Sistemlerinin Karşılaştırması}

Orman yangınları ile mücadelede dünya genelinde kullanılan Orman Yangın Tehlike Oranları Sistemlerinin (YTOS) girdi olarak kullandığ 1 veriler Tablo 2'de gösterilmiştir. 
Tablo 2: Dünya genelinde orman yangınları ile mücadelede karar destek sistemi olarak en fazla kullanılan sistemlerin kullandıkları verilerin karşılaştırmaları

\begin{tabular}{|l|c|c|c|c|c|c|}
\hline \multicolumn{1}{|c|}{ SíSTEM } & Rüzgâr & Bağıl Nem & Sıcaklık & $\begin{array}{c}\text { Yağıș } \\
\text { Miktarı }\end{array}$ & $\begin{array}{c}\text { Yanıcı Madde } \\
\text { Modeli }\end{array}$ & $\begin{array}{c}\text { Tutuşma } \\
\text { Modeli }\end{array}$ \\
\hline Kanada YTOS & Evet & Evet & Evet & Evet & Evet $^{1}$ & Evet $^{1}$ \\
\hline ABD YTOS & Evet & Evet & Evet & Evet & Evet $^{2}$ & Evet \\
\hline McArthur Orman YTİ & Evet & Evet & Evet & Evet & Evet $^{3}$ & Hayır \\
\hline McArthur Çayır YTİ & Evet & Evet & Evet & Hayır & Evet $^{4}$ & Hayır \\
\hline
\end{tabular}

${ }^{1}$ Ancak MYI Sisteminde bulunmaz, sadece standart yanıcı maddeler için geçerlidir.

${ }^{2}$ Amerikan sisteminde 4 farkl y yanıcı madde modeli bulunmaktadır.

${ }^{3}$ Sadece okaliptüs ormanları için geçerlidir.

${ }^{4}$ Çayır yangınlarına dayanır ve sadece kuru ot biyokütlesini temel alır.

Sistem yapılarının içeriği ve sistemin ihtiyaç duyduğu girdiler de ilgili tabloda incelenmiştir (Tablo 3). Tablo incelendiğinde ABD YTOS'un diğer sistemlere göre karmaşı bileşenler içerdiği ve girdi olarak hızlı ve kolay elde edilemeyecek verileri kullandığı anlaşılabilmektedir.

Tablo 3: Dünya genelinde orman yangınları ile mücadelede karar destek sistemi olarak en fazla kullanılan sistemlerin kullandıkları verilerin karşılaştırılmaları

\begin{tabular}{|c|c|c|c|}
\hline SISTEM & ABD YTOS & KANADA YTOS & McArthur YTİ \\
\hline Girdiler & $\begin{array}{l}\text { - Sicaklık } \\
\text { - Bağıl Nem } \\
\text { - Rüzgâr Hızı } \\
\text { - Bulutluluk } \\
\text { - Yağış süresi } \\
\text { - Yanıcı Madde Modelleri } \\
\text { - Eğim Sinıfları } \\
\text { - İklim Sınıfları }\end{array}$ & $\begin{array}{l}\text { - Sicaklık } \\
\text { - Bağıl Nem } \\
\text { - Rüzgâr Hızı } \\
\text { - Yağış Miktarı } \\
\text { - Topoğrafya } \\
\text { - Yanıcı Madde Modeli }\end{array}$ & $\begin{array}{ll}\text { - } & \text { Sicaklık } \\
\text { - } & \text { Bağıl Nem } \\
\text { - } & \text { Rüzgâr Hızı } \\
\text { - } & \text { Yağış Miktarı }\end{array}$ \\
\hline Çıktılar & 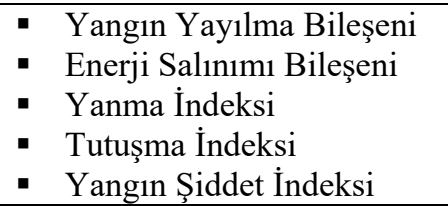 & $\begin{array}{ll}\text { - } & \text { Başlangıç Yayılma İndeksi } \\
\text { - } & \text { Meteorolojis Yanicı Yanginde İndeksi } \\
\end{array}$ & $\begin{array}{l}\text { - Yangın Tehlike } \\
\text { İndeksi } \\
\text { - Kuraklık Faktörü }\end{array}$ \\
\hline $\begin{array}{l}\text { Geçerli Olduğu } \\
\text { Alan Yapısı }\end{array}$ & $\begin{array}{l}\text { Düz açık alanlar ve atmosferik } \\
\text { etkilere açık eğimli alanlar }\end{array}$ & $\begin{array}{l}\text { Belirli kapalılığa sahip orman } \\
\text { alanları }\end{array}$ & $\begin{array}{l}\text { Atmosferik etkilere } \\
\text { açık düz alanlar }\end{array}$ \\
\hline Model Yapıs1 & Fiziksel modeller & $\begin{array}{l}\text { Ampirik modeller ve yarı fiziksel } \\
\text { modeller }\end{array}$ & Ampirik modeller \\
\hline
\end{tabular}

Dünya genelinde öne çıkan sistemler değerlendirildiğinde, sistem yapısı, kullanım kolaylığı ve farklı coğrafyalara uygulanabilirliği bakımından Kanada YTOS ön plana çıkmaktadır. Ancak, Kanada YTOS boreal kuşak ormanları için geliştirilmiş olup farklı bölgelerde (özellikle Akdeniz orman ekosistemleri) herhangi bir uyarlamaya tabi tutulmadan kullanılması yanıltıcı sonuçlar verebilmektedir (Dimitrakopoulos vd. 2011). Bu yüzden sistem yapısı itibari ile kullanışlı olan Kanada YTOS, farklı bölgeler için kullanılan modellerin yanıcı madde özelliklerine göre uyarlanması ile kullanılabilir.

\subsection{Türkiye Orman Yangın Tehlike Oranları KDS Kavramsal Çerçevesi}

Dünya genelinde kullanılan KDS sistemleri değerlendirildiğinde Türkiye yangın yönetim planlama çalışmalarına katkı sağlayabilecek bir KDS'nin kavramsal olarak sahip olması gereken birtakım özellikler belirlenmiştir. YTOS KDS öncelikle topoğrafya gibi sabit; hava halleri, yanıcı madde özellikleri, demografik yapı gibi değişken çevre faktörlerini değerlendirerek, yangınların önceden tespit edilmesi için tahminler geliştirebilecek, yangın anında uygulayıcılara müdahale seçenekleri konusunda öneriler sunabilecek ve yangın sonrası yapılabilecek faaliyetlerde karar vericilere yardımcı olabilecek nitelikte olmalıdır. Bu bağlamda YTOS KDS sisteminin sahip olması gereken özellikler aşağıda sıralanmıştır. Sistem; 
- Hızlı ve kolaylıkla ulaşılabilir veriler ile çalışabilmeli,

- Elde edilen verileri uygun modeller ile yorumlayarak, yangın öncesi, yangın anı ve yangın sonrası yapılacak potansiyel uygulamaları belirleyebilmeli,

- $\quad$ Elde ettiği sonuçları anlaşılır bir şekilde karar vericilere sunabilmeli,

- Modüler bir tasarıma sahip olmalı ve sistemin yapısı, değişen şartlara kolaylıkla uyarlanabilmeli,

- Birbiri ile uyumlu çalışabilen bileşenlerden oluşmalı,

- Günümüz teknolojilerine uygun, hızlı çalışabilen ve kullanıcı dostu bir yapıda olmalıdır.

Bu kapsamda, Türkiye Orman Yangın Tehlike Oranları Karar Destek Sistemi (TOYTOS)’nin kavramsal çerçevesi, sistem yapısı ve hiyerarşisi oluşturulmuştur (Şekil 5).

TOYTOS KDS'nin yapısı girdiler, modelleme, sistem ana bileşenleri, yazılım, doğrulama ve karar destek sistemi ile çıktılar temel bölümlerinden oluşmaktadır. Girdiler bölümünde, KDS'nin ihtiyaç duyduğu sabit ve değişken çevre faktörleri ile geçmiş yangınlara ilişkin zamansal, mekânsal ve öznitelik verileri belirlenmiştir. Belirlenen girdiler, modellenerek, sistem ana bileşenlerinin altyapısı oluşturulmuştur. Daha sonra, KDS'nin ana gövdesini oluşturan sistem ana bileşenlerinin bağlantıları ve hiyerarşik yapıları belirlenerek yazılım, doğrulama ve karar destek sistemi oluşturulmuştur $\mathrm{Bu}$ sayede $\mathrm{KDS}$, orman yangın yönetim planlama ve yangınla mücadele çalışmalarında yardımcı olabilecek çıktılar elde edecek şekilde tasarlanmıştır.

TOYTOS KDS temel yapı ve sistem ana bileşenleri açısından Dünya genelinde kullanımda olan Kanada, ABD ve Avustralya sistemleri ile benzerlikler taşımakla birlikte, temel farklılık sistem bileşenlerini oluşturan model farklılıklarından kaynaklanmaktadır. Örneğin, TOYTOS KDS'de, Meteorolojik Yangın İndeksi sistemi ve Yangın Davranışı Tahmin Sisteminde kullanılan modeller diğer sistemlerin aksine dinamik bir yapıya sahip olup, sabit yanıcı madde modelleri yerine değişken yanıcı madde özelliklerini dikkate almaktadır.

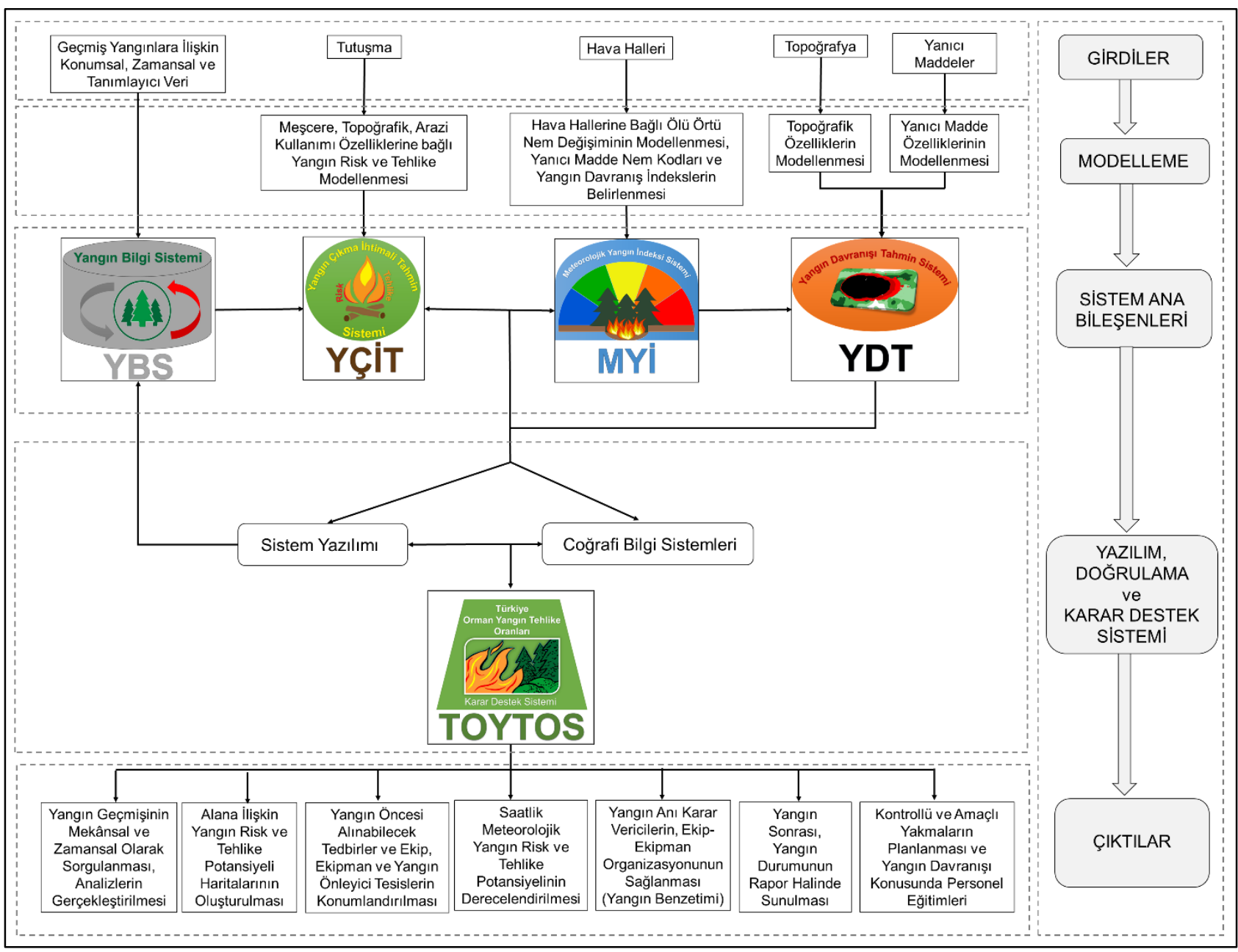




\subsubsection{Yangın Bilgi Sistemi Yapısı}

Yangın Bilgi Sistemi, orman yangınları ile ilgili tüm mekânsal, zamansal ve tanımlayıcı bilgilerin kullanıcı dostu bir arayüz yardımıyla girildiği, akıllı sorgulama ve analizlerin gerçekleştirildiği bir alt sistemdir (Şekil 6).

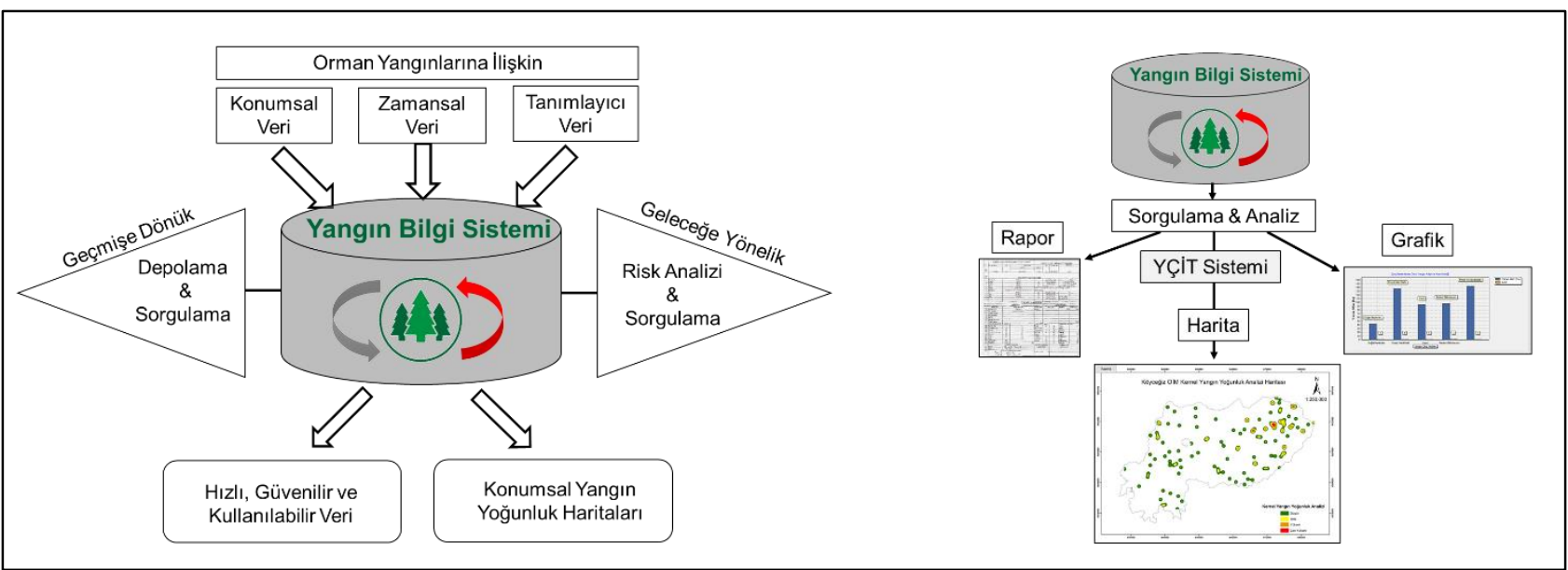

Şekil 6: Yangın Bilgi Sistemi (YBS) sistem tasarımı

YBS sisteminde kullanılacak girdiler, 285 Sayılı Orman Yangınlarının Önlenmesi ve Söndürülmesinde Uygulama Esaslarına (OGM 1995) uygun olarak hazırlanmıştır. YBS veri tabanının rahat kullanımı için, Orman Genel Müdürlüğü’nün yangın formlarında bulunan bilgilerin (konum, meşcere tipi, yangın türü, yangına ilişkin meteorolojik veriler vb.), kullanıcılar tarafindan kolayca girilebilmesini sağlayacak kullanıcı dostu bir veri tabanı arayüzü bulunmaktadır. Aynı zamanda, ilgili sistemde sorgulama ve analiz bölümleri de bulunmaktadır. Sorgulama ve analiz sonuçları metin, grafik ve harita çıktıları şeklinde alınabilmektedir. Örneğin kullanıcı, belirlenen alanda meydana gelmiş olan örtü ve tepe yangınlarının grafiksel olarak dökümünü gerçekleştirebilmektedir.

YBS, aynı zamanda geçmişe dönük yangınların zamansal ve mekânsal analizi ile TOYTOS'un alt sistemi olan YÇİT sistemine girdi sağlamaktadır. Geçmiş yangın verilerinden (coğrafi koordinatları ve öznitelik bilgileri) hareketle yangın yoğunluk haritaları oluşturulabilmekte; aynı zamanda, sistemin depoladığı yangın gözetleme kulelerinin mekânsal bilgisi ile kule görünürlük analizleri de gerçekleştirilebilmektedir.

\subsubsection{Yangın Çıkma İhtimali Tahmin Sistemi Yapısı}

Yangın çıkma ihtimali tahmin sistemi, bazı sabit ve değişken çevre faktörlerini dikkate alarak yangın risk ve tehlike potansiyelini belirleyen alt sistemdir. Sistem tasarımında, alanın güncel özeliklerine bağlı olarak yangın risk ve tehlike potansiyeli modellemesi gerçekleştirilmektedir. Bu sisteme girdi sağlayan parametreler; ağaç türü, gelişim çağ1 gibi meşcere özellikleri, arazi eğimi ve bakısı gibi topoğrafik özellikler, arazi kullanımı ve demografik özelliklerdir. YÇíT sisteminin genel yapısı ve tasarımı Şekil 7'de gösterilmiştir.

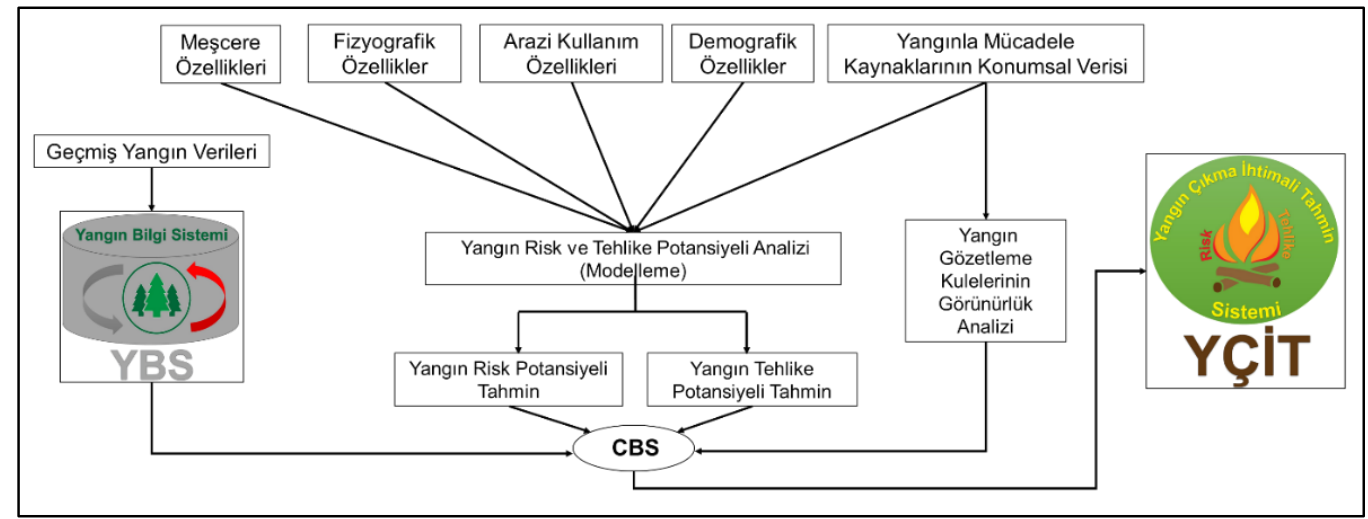

Şekil 7: Yangın Çıkma Ihtimali Tahmin (YÇiT) sistem tasarımı

Ayrıca YÇİT sistemi, YBS sisteminden elde ettiği geçmiş yangın verileri ile mekânsal yangın yoğunluk analizi ve yangın gözetleme kulesi görünürlük analizlerini de gerçekleştirebilmektedir. 


\subsubsection{Meteorolojik Yangın İndeksi Sistemi Yapısı}

Meteorolojik Yangın İndeksi Sistemi, standart bir yanıcı madde tipinde, yanıcı madde nemine bağlı olarak yanıcı maddelerin tutuşabilirliğini belirleyen ve yangının başlaması durumunda potansiyel yangın yayılma oranı ve yangın şiddeti hakkında bilgi veren alt sistemdir. Sistem, yanıcı madde nemini, mevcut hava halleri verileri ile hesaplayarak, yanıcı madde kodları ve yangın davranış indeksleri yardımıyla yangın risk ve tehlike potansiyelini saatlik olarak derecelendirir. MYİ sisteminin genel yapısı ve tasarımı Şekil 8'de gösterilmiştir.

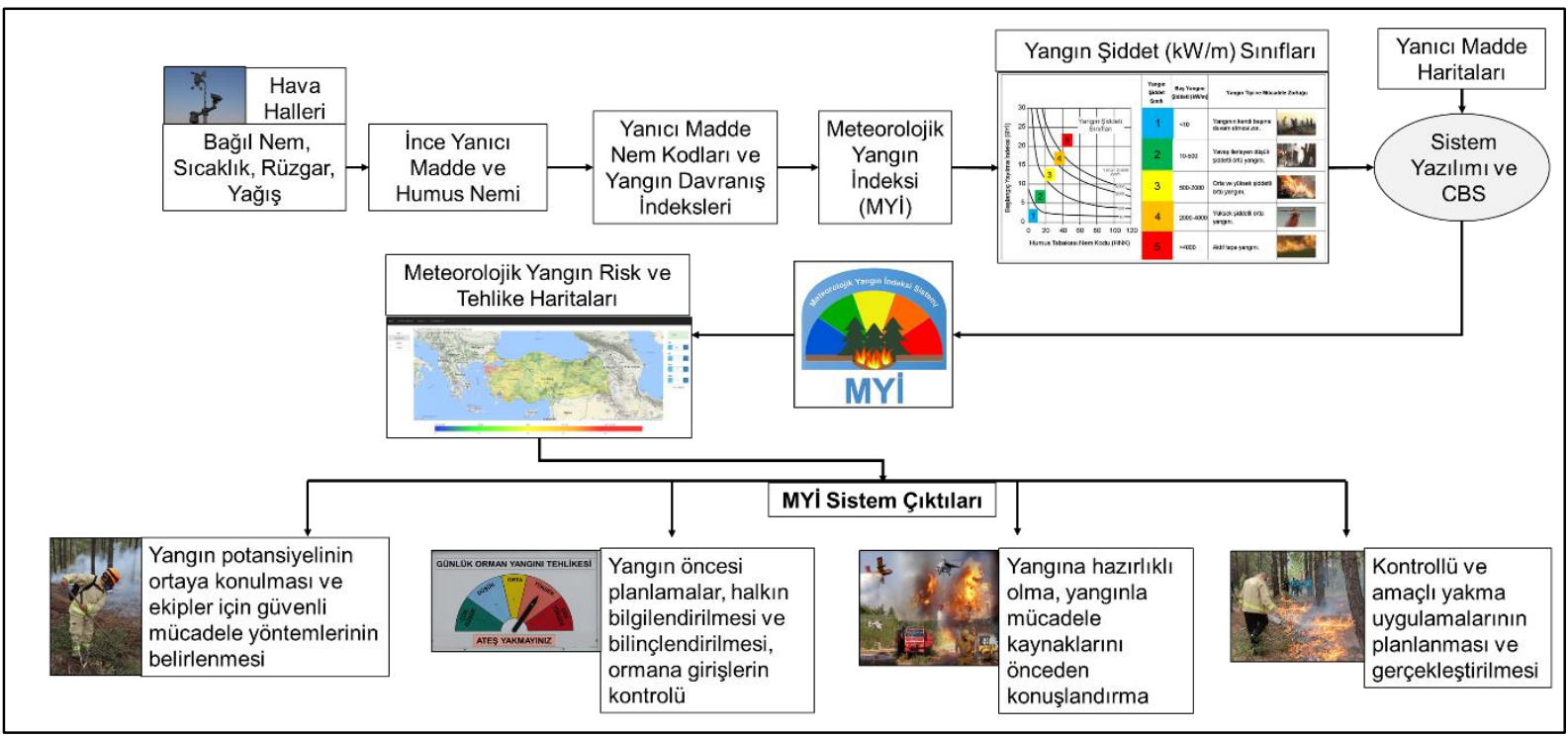

Şekil 8: Meteorolojik yangın indeksi sistem tasarımı

Meteorolojik Yangın İndeksi Sistemi, orman yangınları açısından kritik öneme sahip yanıcı madde nem verisini, Yangın Davranışı Tahmin Sistemi’ne sağlamaktadır.

\subsubsection{Yangın Davranışı Tahmin Sistem Yapısı}

Yangın Davranışını Tahmin Sistemi, yangın davranışını farklı hava halleri, topoğrafya ve yanıcı madde özelliklerine bağlı olarak tahmin etmeye çalışan bir alt sistemdir. Yangın davranışı, yanıcı madde, topoğrafya ve hava hallerine bağlı olarak değişim göstermektedir. Orman yangınları ile başarılı ve etkili bir şekilde mücadele edilebilmesi ve yangın öncesi ve yangın sonrası planlamaların sağlıklı bir şekilde yapılabilmesi için, farklı yanıcı madde tiplerinde yangın davranışının sağlıklı bir şekilde ortaya konulması gerekmektedir. YDT sisteminin genel yapısı ve tasarımı Şekil 9'da gösterilmiştir.

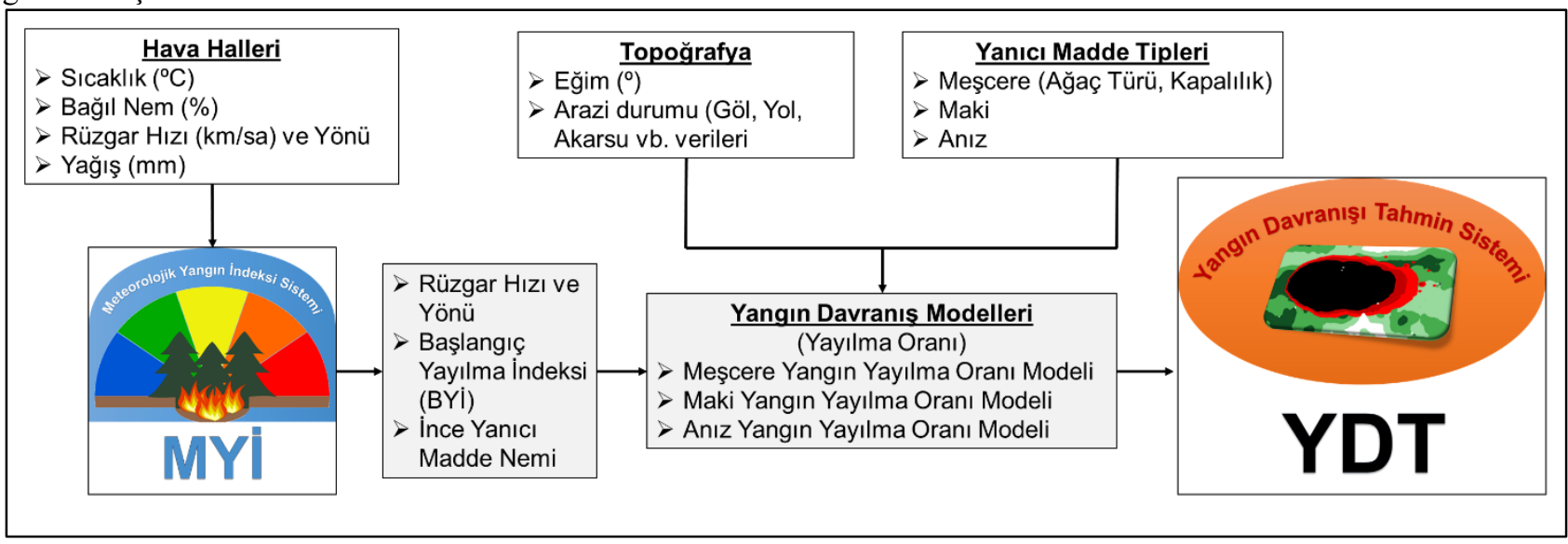

Şekil 9: Yangın davranışı tahmini sistem tasarımı

Yangın davranışı modeli, her hangi bir yerde çıkabilecek bir yangının hava halleri, topoğrafya ve yanıcı madde özelliklerine bağlı olarak sergileyeceği davranışı sayısal olarak ortaya koyar. Yangın davranışı tahmininin doğruluğu, sistemin girdi olarak kullandığı doğru ve güvenilir yanıcı madde özellikleri, topoğrafya ve meteorolojik verilere bağlıdır. 
YDT Sistemi, Rüzgâr Hızı ve Yönü, Başlangıç Yayılma İndeksi ve İnce Yanıcı Madde Nem verilerini doğrudan Meteorolojik Yangın İndeksi Sisteminden almaktadır. Sisteme girdi sağlayan eğim ve yangın davranışında farklılık oluşturan doğal ve yapay engellere ilişkin bilgiler ise, orman amenajman planları envanter verilerinden elde edilebilecek nitelikteki verilerdir.

\section{Sonuç}

Çalışma kapsamında tasarımı gerçekleştirilen KDS yapısı çok sayıda bileşenlerden oluşmasına rağmen, sistem hızlı ve kolay elde edilebilir girdiler ile çalışmaktadır. Bu girdileri, yangın organizasyonlarının kolay erişim sağlayabileceği orman amenajman planlarının içerdiği yanıcı madde özelliklerine ilişkin veriler ile hava hallerine ilişkin veriler oluşturmaktadır. Sistemde, ilgili plan veri tabanlarının içerdiği topoğrafik özelliklere ilişkin öznitelik verileri de kullanılmaktadır. Ayrıca, ilgili planların içerdiği detay verileri ile alana ilişkin yol durumu, su kaynakları gibi bilgiler de yanıcı madde haritalarına işlenebilmektedir. Böylelikle, sistem kullanımı, dış veriye bağımlılı̆̆ı en aza indirebilecek şekilde gerçekleştirilebilmektedir. Sistemin çalışabilmesi için ihtiyaç duyulan hava hallerine ilişkin veriler ise günümüz teknolojisinin yardımıyla kolay ulaşılabilir bir yapıdadır. Hava halleri verileri herhangi bir çevrimiçi veri sağlayıcısından konumsal olarak elde edilebilir.

Bu özellikler dikkate alındığında, TOYTOS KDS'nin modelleme ve yazılımı gerçekleştirilip, yangın yöneticileri tarafından uygulamada kullanılması durumunda elde edilebilecek sonuçlar aşağıda sıralanmıştır. TOYTOS KDS ile yangın yöneticileri;

- Orman yangınları ile mücadelede kullanılabilecek verileri depolayabilecek, veriler üzerinde analiz ve sorgulama yapabilecektir.

- Belirlenen alanda gerçekleşmiş geçmiş yangınlara ilişkin mekânsal değerlendirmeler yapabilecektir.

- Yangın risk ve tehlike potansiyelini, sabit ve değişken çevre faktörlerine bağlı olarak istenilen bir alan için derecelendirebilecek, mekânsal sorgulamalar yapabilecektir.

- Halkı çıkabilecek bir orman yangınına karşı uyarma veya orman içi faaliyetleri sınırlamak gibi önleyici tedbirlerin planlanması ve uygulanmasını kolaylıkla gerçekleştirebilecektir.

- Orman yangınlarına hazırlıklı olma faaliyetleri kapsamında, yangın tehlike potansiyelini azaltıcı aralama ve budama gibi silvikültürel faaliyetlere ilişkin potansiyel alanları önceden belirleyebilecektir.

- Yangın gözetleme faaliyetlerinin planlanması, eldeki kaynakların etkili ve verimli kullanılabilmesi için sayısal veri elde edebilecek ve bu verileri raporlayabilecektir. Ayrıca potansiyel gözetleme noktaları ve rotalarını belirleyebilecektir.

- Hava halleri değişimlere göre, anlık olarak yangın potansiyelini tespit edebilecek, aynı zamanda yangınla mücadele ekipleri için güvenli mücadele yöntemlerini belirleyebilecektir.

- Yangın davranışını, hava halleri, topoğrafya ve yanıcı madde özelliklerine bağlı olarak doğru ve hızlı olarak tahmin edebilecektir. Ayrıca, yangının potansiyel etkilerini önceden kestirerek, kaynak tasarrufu konusunda destek alabilecektir.

- Yangına yapılabilecek ilk müdahale ve devam eden bir yangınla mücadele için yöntem, taktik ve stratejilerini belirleyebilecektir.

- Kontrollü ve amaçlı yakma çalışmaların zamansal ve mekânsal planlanması yapabilecek ve yakma uygulamalarını gerçekleştirebilecektir.

- Geçmiş verileri kullanarak, yangının tekrardan benzetimini yapabilecektir. Böylece, yangının potansiyel etkilerini raporlayabilecek ve geçmiş yangınlar üzerinde ayrıntılı analizler gerçekleştirilebilecektir.

- Orman yangın yönetimi konusunda ülkemizde yapımına kısa süre önce başlanan, işletme ve şeflik bazında hazırlanabilen "Yangın Yönetim Planları" içeriğini kolaylıkla hazırlayabilecektir.

- Orman yangınları ile mücadelede teknik eleman, işçi ve diğer kurum ve kuruluşlardaki paydaşlara, yangınları anlama ve karar verme aşamalarında daha etkili eğitimler verebileceklerdir.

\section{Kaynaklar}

Alexander M.E., Stocks B.J., Lawson B.D., (1996), The Canadian forest fire danger rating system, Bombardier Inc., Canadair, Montreal, PQ. ss.6-9.

Baş R., (1965), Türkiye'de Orman yanginlari problemi ve bazi klimatik faktörlerin yangınlara etkileri üzerine araştirmalar, Orman Genel Müdürlüğü Yayınları, Ankara, Türkiye 421 ss.

Bilgili E., (1997), Forests and forest fires in Turkey, International Forest Fire News, 17(1), 15-21.

Bilgili E., (1999), The Use of Decision Support Systems in Fire Management Planning, Orman Yangınlarının Önlenmesi ve Mücadelesi Semineri, 18-22 Mayıs, Fethiye, Muğla.

Bilgili E., Coskuner K.A., (2015), Towards Turkish National Fire Danger Rating System as a Decision Support System, Proceedings 6th International Wildland Fire Conferance, Pyeongchang, South Korea, ss.16-17.

Bilgili E., Sağlam B., (2003), Fire behavior in maquis fuels in Turkey, Forest Ecology and Management, 184(1-3), 201-207. 
Bilgili E., Sağlam B., Başkent E.Z., (2001), Yangın amenajmani planlamalarinda yangin tehlike oranlari ve Coğrafi Bilgi Sistemleri, KSÜ Fen ve Mühendislik Dergisi, 4(2), 288-297.

Boer M.M., Sadler R.J., Wittkuhn R.S., McCaw L., Grierson P.F., (2009), Long-term impacts of prescribed burning on regional extent and incidence of wildfires-Evidence from 50 years of active fire management in SW Australian forests, Forest Ecology and Management, 259(1), 132-142.

Burgan R. E., (1988), Revisions to the 1978 National Fire-Danger Rating System, Res. Pap. SE-273 Department of Agriculture, Forest Service, Southeastern Forest Experiment Station, Asheville, North Carolina, USA, 44ss.

Carlson J.D., Bradshaw L.S., Nelson R.M., Bensch R.R., Jabrzemski R., (2007), Application of the Nelson model to four timelag fuel classes using Oklahoma field observations: model evaluation and comparison with National Fire Danger Rating System algorithms, International Journal of Wildland Fire, 16(2), 204-216.

CFDG, (1992), Development and structure of the Canadian Forest Fire Behavior Prediction System, Information Report ST-X-3 Fire Danger Group and Science and Sustainable Development Directorate, Ottawa, Canada, 66ss.

Chandler C., Cheney P., Thomas P., Trabaud L., Williams D., (1983), Fire in forestry. Volume 1. Forest fire behavior and effects Volume 2. Forest fire management and organization, John Wiley \& Sons, Inc, New York, USA, 450ss.

Chuvieco E., Aguado I., Yebra M., Nieto H., Salas J., Martin M.P., Vilar L., Martinez J., Martin S., Ibarra,P., de la Riva J., Baeza J., Rodriguez F., Molina J. R., Herrera M.A., Zamora R., (2010), Development of a framework for fire risk assessment using remote sensing and geographic information system technologies, Ecological Modelling, 221(1), 46-58.

Countryman C.M., (1966), Rating Fire Danger by the Multiple Basic Index System, Journal of Forestry, 64(8), 531-536.

Çanakçıŏlu, H., (1985) Orman Koruma, İstanbul Üniversitesi Orman Fakültesi Yayınların, İstanbul, Türkiye, 486ss.

Çanakçıŏlu, H., (1988), Yangın Tehlike İndekslerinden Yararlanılan Alanlar, Türkiye Ormanlarını Yangından Koruma Semineri, 1 4 Mayis, Ankara, ss.153-162.

de Groot, W.J., Field R.D., Brady M.A., Roswintiarti O., Mohamad M., (2006), Development of the Indonesian and Malaysian Fire Danger Rating Systems, Mitigation and Adaptation Strategies for Global Change, 12, 165-180.

de Groot, W.J., Goldammer G.J., Keenan T., Brady M., Lynham T.J., Justice C.O., Csiszar, I.A., O'Loughlin K. (2006), Developing a global early warning system for wildland fire, 5th International Conference on Forest Fire Research, Figueira da Foz, Portugal 12.

Deeming J.E., Burgan R.E., Cohen J.D., (1978), The National Fire-Danger Rating System, U.S. Department of Agriculture, Forest Service, Intermountain Forest and Range Experiment Station, INT-39.

Deeming J.E., Lancester J.W., Fosberg M.A., Furman R.W., Schroeder M.J., (1972), The National Fire-Danger Rating System, Fort Callins, Colorado, $165 \mathrm{ss}$.

del Hoyo L.V., Isabel M.P.M., Vega F.J.M., (2011), Logistic regression models for human-caused wildfire risk estimation: analysing the effect of the spatial accuracy in fire occurrence data, European Journal of Forest Research, 130(6), 983-996.

Dimitrakopoulos A.P., Bemmerzouk A.M., (2003), Predicting live herbaceous moisture content from a seasonal drought index, International Journal of Biometeorology, 47, 73-79.

Dimitrakopoulos A.P., Bemmerzouk A.M., Mitsopoulos I.D., (2011), Evaluation of the Canadian fire weather index system in an eastern Mediterranean environment, Meteorological Applications, 18(1), 83-93.

Fogarty L.G., Pearce H.G., Catchpole W.R., Alexander M.E., (1998), Adoption vs Adaptation: Lessons from applying the Canadian Forest Fire Danger Rating System in New Zealand. III International Conference on Forest Fire Research, 14th Conference on Fire and Forest Meteorology, 16-20 November, Luso, Portugal.

Fosberg M.A., Micheal A., (1971), Moisture content calculations for the 100-hour timelag fuel in fire-danger rating, Res. Note RM199 Rocky Mountain Forest and Range Experiment Station, Fort Collins, Colorado, USA, 7ss.

Fosberg M.A., Micheal A., Deeming J.E., (1971), Derivation of the 1- and 10- hour timelag fuel moisture calculations for firedanger rating, Res. Note RM-207 Rocky Mountain Forest and Range Experiment Station, Fort Collins, Colorado, USA, 8ss.

Fox-Hughes P., Matthews S., Jakob D., Sauvage S., Kenny B., Su C.H., Hollis J., Grootemaat S., Eizenberg N., Steinle P., (2018), Coimbra, Portugal, Reanalysis of climatology of Australian protoype fire danger rating system: 192. 8th International Conferance of Forest Fire Research, GOFC-GOLD, (2003), Monitoring Global Change: Canada's Contribution. Natural Resources Canada, Edmonton, AB.

Griffiths D., (1999), Improved formula for the drought factor in McArthur's Forest Fire Danger, Aust. For., 62(2), 202-206.

Hirsch K.G., (1996), Canadian Forest Fire Behavior Prediction (FBP) System: user's guide, Edmonton, Alberta, Canada, 122ss.

Kalabokidis K., Ager A., Finney M., Athanasis N., Palaiologou P., Vasilakos C., (2016), AEGIS: a wildfire prevention and management information system, Natural Hazards and Earth System Sciences, 16(3), 643-661.

Kalabokidis K., Xanthopoulos G., Moore P., Caballero D., Kallos G., Llorens J., Roussou O., Vasilakos C., (2012), Decision support system for forest fire protection in the Euro-Mediterranean region, European Journal of Forest Research, 131(3), 597-608.

Keetch J.J., Byram G. M., (1968), A drought index for forest fire control, Report SE-38 Department of Agriculture, Forest Service, Southeastern Forest Experiment Station, Asheville, North Carolina, USA, 32ss.

Kourtz P.H., Todd J.B., (1991), Predicting the daily occurrence of lightning-caused forest fires, Information Report PI-X-112 Petawawa National Forestry Institute, Chalk River, Ontario, Canada, 18ss.

Küçük Ö., (2000), Karaçamda yanici madde miktarinin tespiti ve yanici madde özelliklerine bağli yanici madde modelleri, Yüksek Lisans Tezi, K.T.Ü, Fen Bilimleri Enstitüsü, Trabzon.

Küçük Ö., (2004), Yanıcı madde tipleri ve yangın davranışına bağll yangın potansiyelinin belirlenmesi ve haritalanması, Doktora Tezi, K.T.Ü, Fen Bilimleri Enstitüsü Trabzon.

Küçük Ö., Bilgili E., Sağlam B., Durmaz B.D., Baysal I., (2007), The Studies to Support a Fire Danger Rating System in Turkey, Kastamonu University, Journal of Forestry Faculty, 7(1), 104-109.

Lawson B.D., Stocks B.J., Alexander M.E., Van Wagner C.E., (1985), A system for predicting fire behavior in Canadian forests, Proceedings of the 8th Conference on Fire and Forest Meteorology, Detroit, Michigan, USA., 85, ss.6-16.

Lee B.S., Alexander M.E., Hawkes B.C., Lynham T.J., Stocks B.J., Englefield P., (2002), Information systems in support of wildland fire management decision making in Canada, Computers and Electronics in Agriculture, 37(1-3), 185-198. 
Lopez A.S., San-Miguel-Ayanz J., Burgan R.E., (2002), Integration of satellite sensor data, fuel type maps and meteorological observations for evaluation of forest fire risk at the pan-European scale, International Journal of Remote Sensing, 23(13), 27132719.

Martell D.L., (2001), Forest Fires, Chapter 15-Forest Fire Management, E.A. Johnson, K. Miyanishi editors, Academic Press, San Diego, ss.527-583.

Martell D.L., Bevilacqua E., Stocks B.J., (1989), Modeling Seasonal-Variation in Daily People-Caused Forest Fire Occurrence, Canadian Journal of Forest Research-Revue Canadienne De Recherche Forestiere, 19(12), 1555-1563.

Matthews S., Fox-Hughes P., Grootemaat S., Heemstra S., Hollis J., Kenny B., Sauvage S., Shackleton C., Short L., Sparkles D., (2018) Coimbra, Portugal, Building the prototype for a new National Fire Danger Rating System for Australia, 8th International Conferance on Forest Fire Research, Coimbra, Portugal, ss.1359-1362.

McArthur A.G., (1958), The preparation and use of fire danger tables, Fire Weather Conference, 15-17 July, Melbourne, Australia.

McArthur A.G., (1960), Fire danger rating tables for annual grasslands, Forestry and Timber Bureau, Mimeograph, Australia $15 \mathrm{ss.}$

McArthur A.G., (1962), Control burning in eucalypt forests, Forestry and Timber Bureau, Leaflet, Australia, $7 \mathrm{ss}$.

McArthur A.G., (1966), Weather and grassland fire behaviour, Forestry and Timber Bureau, Leaflet, Australia, 16ss.

McArthur A. G., (1967), Fire behaviour in eucalypt fuels, Forestry and Timber Bureau, Leaflet, Australia, 13ss.

Merrill D.F., Alexander M.E., (1987) Glossary of forest fire management terms, Pub. NRCC No. 26516, Canadian Committee on Forest Fire Management, National Research Council of Canada, Ottawa.

Mol T., (1988) Yangın Tehlike Oranlarl, Türkiye Ormanlarını Yangından Koruma Semineri, 1-4 Mayıs, Ankara, ss. 130-139.

Moreira F., Viedma O., Arianoutsou M., Curt T., Koutsias N., Rigolot E., Barbati A., Corona P., Vaz P., Xanthopoulos G., Mouillot F., Bilgili E., (2011), Landscape - wildfire interactions in southern Europe: Implications for landscape management, Journal of Environmental Management, 92(10), 2389-2402.

Nelson R.M., (2000), Prediction of diurnal change in 10-h fuel stick moisture content, Canadian Journal of Forest Research-Revue Canadienne De Recherche Forestiere, 30(7), 1071-1087.

OGM (2016), Orman Yangın Eylem Planı, Orman Genel Müdürlüğü Orman Yangınları ile Mücadele Dairesi Başkanlığı, Ankara, Türkiye, 260ss.

OGM (2017), Orman yangınlart ile mücadele faaliyetleri 2017 yılı değerlendirme raporu, Orman Genel Müdürlüğü Orman Yangınları ile Mücadele Dairesi Başkanlığı, Ankara, Türkiye, Ankara 130ss.

Öymen T., (1989). Yangın Davranış Tehlike Sinyalleri ve İnterpretasyonları, Orman Yangınlarıyla Savaş Semineri, Ankara 28: 31 35.

Pearce H.G., Alexander M. E., (2015), Bethesda, MD, Fire danger ratings associated with New Zealand's major pine plantation wildfires, 12th Conference on Fire and Forest Meteorology, October 26-28, 1993, 94-02: 534-543.

Pettinari M.L., Pyne, S. J., (1984), Global Fuelbed Dataset. Introduction to wildland fire. Fire management in the United States, John Wiley \& Sons, New York.

Rothermel, R. C., (1972), A mathematical model for predicting fire spread in wildland fuels, Report INT-115 Department of Agriculture, Forest Service, Intermountain Forest and Range Experiment Station, Ogden,Utah, USA, 48ss.

Rowe J.S., (1972), Forest Regions of Canada, Can. For. Serv. Ont. Publ., Ottawa.

Sağlam B., (2002), Meteorolojik faktörlere bağli yanici madde nem içerikleri ve maki tipi yanici maddelerde yangin davranişi, Doktora Tezi, K.T.Ü, Fen Bilimleri Enstitüsü, Trabzon.

Sağlam B., Bilgili E., Durmaz B.D., Kadiogullari A.İ., Küçük Ö., (2008), Spatio-temporal analysis of forest fire risk and danger using Landsat imagery, Sensors, 8(6), 3970-3987.

San-Miguel-Ayanz J., Moreno J.M., Camia A., (2013), Analysis of large fires in European Mediterranean landscapes: Lessons learned and perspectives, Forest Ecology and Management, 294, 11-22.

Shim J.P., Warkentin M., Courtney J.F., Power D.J., Sharda R., Carlsson C., (2002), Past, present, and future of decision support technology, Decision Support Systems, 33(2), 111-126.

Stocks B.J., Lawson B.D., Alexander M.E., Van Wagner C.E., McAlpine R.S., Lynham T.J., Dube D.E., (1989), The Canadian Forest Fire Danger Rating System-an Overview, Forestry Chronicle, 65(6), 450-457.

Taylor S.W., (2001), Considerations for Applying the Canadian Forest Fire Danger Rating System in Argentina, Canadian Forest Service, Pacific Forestry Centre: Victoria, BC, Canada, 25ss..

Taylor S.W., Alexander M.E., (2003), Canada, Considerations in developing a national forest fire danger rating system, XII World Forestry Congress, Quebec, B. Forests for the Planet B1. Status and trends 0726-B1

TOGTAG (2008), Farklı Eğim Grubu ve Nem Koşullarında Maki Tipi Yanıcı Maddelerde Yangın Davranışının Belirlenmesi ve Coğrafi Bilgi Sistemleri Kullanılarak Haritalanması, Proje Sonuç Raporu TOGTAG 105O523, Türkiye Bilimsel ve Teknolojik Araștırma Kurumu, Ankara, Türkiye 56ss.

TOGTAG (2007), Genç Kızılçam Meşcereleri ve Maki Tipi Yanııı Maddelerde Yangın Davranışının Belirlenmesi ve Coğrafi Bilgi Sistemleri Kullanılarak Haritalanması, Proje Sonuç Raporu TOGTAG 3375, Türkiye Bilimsel ve Teknolojik Araştırma Kurumu, Ankara, Türkiye 82ss.

TOVAG (2011), Türkiye Ulusal Yangın Tehlike Oranları Sistemi (TUYTOS) ’ne Doğru. Bölüm I: Yangın Davranışı Tahmin Sistemi, Proje Sonuç Raporu TOVAG 108O327, Türkiye Bilimsel ve Teknolojik Araştırma Kurumu, Ankara, Türkiye 89ss.

TOVAG (2015), Türkiye Orman Yangın Tehlike Oranları Sistemi (TOYTOS)'ne Doğru. Bölüm II: Meteorolojik Yangın İndeksi Sistemi, Proje Sonuç Raporu TOVAG 112O809, Türkiye Bilimsel ve Teknolojik Araştırma Kurumu, Ankara, Türkiye 74ss.

Tymstra C.B., R.W., Wotton B.M., Taylor S.W., Armitage, O.B., (2010), Development and Structure of Prometheus: the Canadian Wildland Fire Growth Simulation Model, Information Report NOR-X-417 Northern Forestry Centre Canadian Forest Service, Edmonton, Alberta, Canada, 102ss..

URL-1, (2018), National Fire Danger Rating System (Nfdrs) Proposed Updates, https://www.wfas.net/nfdrs2016, [Erişim 09 Kasım 2018].

URL-2, (2018), The European Forest Fire Information System (EFFIS), http://forest.jrc.ec.europa.eu/effis/applications/currentsituation/, [Erişim 11 Kasım 2018]. 
URL-3, (2018), Global Wildfire Information System (GWIS), http://gwis.jrc.ec.europa.eu, [Erişim 09 Ekim 2018].

Van Nest T.A., Alexander M.E., (1999), Systems for rating fire danger and predicting fire behavior used in Canada, National Interagency Fire Behavior Workshop, Phoenix, Arizona, USA, ss.1-13.

Van Wagner C.E., (1974), Structure of the canadian forest fire weather index, Publication No: 1333, Canadian Forestry Service, Ottawa, Canada, 49 ss.

Van Wagner C.E., (1987), Development and structure of the Canadian forest fire weather index system, Publication No: 1333, Canadian Forestry Service, Ontario, Canada, 48ss.

Van Wagner C.E., (1998), Modelling logic and the Canadian forest fire behavior prediction system, Forestry Chronicle, 74,1, $50-52$.

Van Wagner C.E., Pickett T.L., (1985), Equations and FORTRAN program for the Canadian Forest Fire Weather Index, Forestry Technical Report FTR-35 Canadian Forestry Service, Chalk River, Ontario, Canada, 18ss.

Van Wilgen B.W., Burgan R.E., (1984), Adaptation of the United States Fire Danger Ratin System to fynbos conditions. Part II. Historic fire danger in the fynbos biome., South African Forestry Journal, 129, 66-78.

Viegas D.X., Bovio G., Ferreira A., Nosenzo A., Sol B., (1999), Comparative study of various methods of fire danger evaluation in southern Europe, International Journal of Wildland Fire, 9(4), 235-246.

White R.A., Rush M.F., (1990), The Jiagedaqui fire management project (JIAPRO): an example of international assistance, Information Report NOR-X-309 The Art and Science of Fire Management, Edmonton, AB, ss. 287-296.

Willis C., Wilgen V.W., Tolhurst K., Everson C., D'Abreton P., Pero L., Fleming G., (2001), The Development of a National Fire Danger Rating System for South Africa, Project Report ENV-P-C 2000-073 CSIR Water, Environment and Forestry Technology, Pretoria, South Africa, 89ss.

Wybo J.L., Guarnieri F., Richard B., (1995), Forest-Fire Danger Assessment Methods and Decision-Support, Safety Science, 20(1), 61-70.

Xanthopoulos G., (2007), Forest fire policy scenarios as a key element affecting the occurrence and characteristics of fire disasters, In Proceedings of the 4th International Wildland Fire Conference, 14-17 May, Sevilla, Spain, 11ss.

Bu çalışma, birinci yazarın doktora tezinin bir bölümünden üretilmiştir. 